\title{
A ictiofauna de cabeceiras do rio Tietê, São Paulo, Brasil
}

\author{
Alexandre Pires Marceniuk ${ }^{1,3}$, Alexandre Wagner da Silva Hilsdorf ${ }^{1}$ \& Francisco Langeani ${ }^{2}$ \\ ${ }^{1}$ Laboratório de Genética de Organismos Aquáticos e Aquicultura, Núcleo Integrado de Biotecnologia, \\ Universidade de Mogi das Cruzes - UMC, CP 411, CEP 08701-970, Mogi das Cruzes, SP, Brasil \\ ${ }^{2}$ Laboratório de Ictiologia, Departamento de Zoologia e Botânica, \\ Universidade Estadual Paulista - UNESP, Rua Cristóvão Colombo, 2265, CEP 15054-000, \\ São José do Rio Preto, SP, Brasil, www.ibilce.unesp.br \\ ${ }^{3}$ Autor para correspondência: Alexandre Pires Marceniuk,e-mail: a_marceniuk@hotmail.com
}

MARCENIUK, A.P., HILSDORF, A.W.S. \& LANGEANI, F. The ichthyofauna from the headwaters of the rio Tietê, São Paulo, Brazil. Biota Neotrop. 11(3): http://www.biotaneotropica.org.br/v11n3/en/abstract?inve ntory+bn00311032011

\begin{abstract}
A synthesis of the ichthyofauna of the headwaters of the rio Tietê, based on material from zoological collections and new samplings, is presented. Fifty six species belonging to seven orders and 16 families are recorded to the drainage, increasing previous numbers significantly. The current results show that the headwaters of the rio Tietê possess a singular ichthyofauna composition, diverse from that found in the remaining of the upper Paraná basin, with high level of endemic species and great similarity to the species from coastal drainages. This finding corroborates the hypothesis of past river capture between streams and rivers in both drainages. Among the species occurring in the area surveyed, eight are endemic (14.3\%), 13 are found in the headwaters of rio Tietê and in the coastal drainages of southeastern Brazil (23.2\%), 10 are present throughout the upper Paraná basin (17.9\%), five are found in the upper Paraná basin and in the coastal drainages of southeastern Brazil (8.9\%), while 13 show a broader distribution in the South America drainages (23.2\%), part of which still remains to be identified. Species diversity increased with the discovery of at least five new species belonging to the genera Cyphocharax, Characidium, Astyanax, Pareiorhina and Australoheros, and four new records for Characidium cf. zebra, Scleromystax barbatus, Crenicicla britskii and Synbranchus cf. marmoratus. At least, seven non-native species are recognized to be established in the region, while 10 other are included in red books.
\end{abstract}

Keywords: biodiversity, new species, new records, identification key, conservation.

MARCENIUK, A.P., HILSDORF, A.W.S. \& LANGEANI, F. A ictiofauna de cabeceiras do rio Tietê, São Paulo, Brasil. Biota Neotrop. 11(3): http://www.biotaneotropica.org.br/v11n3/pt/abstract?inventory+bn00311032011

Resumo: Uma síntese das espécies de peixes de cabeceiras do rio Tietê é apresentada com base em material de coleções zoológicas e novas coletas realizadas. São referidas para região 56 espécies pertencentes a sete ordens e 16 famílias, aumentando significativamente números anteriores. Os resultados mostram que as cabeceiras do rio Tietê possuem uma composição ictiofaunistica bastante peculiar, distinta daquela encontrada no restante do Alto rio Paraná, mostrando acentuado grau de endemismo e grande similaridade com bacias hidrográficas litorâneas, corroborando a hipótese de captura de rios da região por drenagens costeiras e vice e versa no passado. Dentre as espécies encontradas na região, oito são endêmicas (14,3\%), 13 são encontradas nas cabeceiras do rio Tietê e drenagens litorâneas da região sudeste do Brasil (23,2\%), dez ocorrem em todo Alto rio Paraná (17,9\%), cinco são encontradas no Alto rio Paraná e drenagens litorâneas da região sudeste do Brasil (8,9\%), enquanto 13 espécies mostram uma ampla distribuição na América do Sul (23,2\%), das quais parte ainda precisa ter a identidade confirmada. A diversidade de espécies é acrescida de pelo menos cinco espécies novas pertencentes aos gêneros Cyphocharax, Characidium, Astyanax, Pareiorhina e Australoheros e quatro novos registros são feitos para Characidium cf. zebra, Scleromystax barbatus, Crenicicla britskii e Synbranchus cf. marmoratus. Pelo menos sete espécies introduzidas estão estabelecidas na região, enquanto outras dez espécies são relacionadas em listas de espécies ameaçadas.

Palavras-chave: biodiversidade, novas espécies, novos registros, chave de identificação, conservação. 


\section{Introdução}

Os peixes, com cerca de 31.600 espécies descritas (Froese \& Pauly 2010), representam mais da metade das espécies de vertebrados conhecidas (Cox \& Moore 2000). A maior diversidade e riqueza de espécies é encontrada em águas tropicais (Lowe-McConnell 1999), particularmente na região Neotropical, onde são conhecidas cerca de 4.475 espécies válidas de água doce, número que pode ser significativamente maior se consideradas espécies não descritas reconhecidas por especialistas (Reis et al. 2003).

Na região Neotropical, a região ictiofaunística do Paraná, formada pelas bacias hidrográficas dos rios da Prata-Uruguai-Paraná-Paraguai, representa o segundo maior sistema de drenagem da América do Sul, com cerca de $3.200 .000 \mathrm{~km}^{2}$, (Lowe-McConnell 1999) e a segunda maior diversidade de espécies de peixes de água doce do continente sul americano (Reis et al. 2003, Langeani et al. 2009). O sistema do Alto rio Paraná corresponde à porção da bacia do rio Paraná situada acima de Sete Quedas (inundada pelo reservatório de Itaipu) e abriga cerca de 310 espécies, pertencentes a 11 ordens e 38 famílias (Langeani et al. 2007). Os rios Grande, Paranaíba, Paranapanema e Tietê são os principais afluentes da margem esquerda do Alto rio Paraná (Souza Filho \& Stevaux 1997). O Tietê é o segundo maior rio do estado de São Paulo, nasce a 840 m de altitude na Serra do Mar, a $22 \mathrm{~km}$ do Oceano Atlântico, e atravessa toda região metropolitana da capital do estado, percorrendo cerca de $1.150 \mathrm{~km}$ até encontrar o rio Paraná, na divisa com o Mato Grosso do Sul em Itapura (Almeida et al. 1981, Ponçano et al. 1981).

A ictiofauna encontrada nos canais principais das drenagens do Alto rio Paraná é caracterizada por espécies de médio e grande porte, normalmente com ampla distribuição geográfica e importância para pesca comercial e de subsistência (Agostinho \& Júlio Junior, 1999, Galves et al. 2009). Em contraste, as espécies encontradas nas cabeceiras de rios e riachos associados são de pequeno porte, têm pouco valor comercial, distribuição geográfica restrita e são bastante dependentes da vegetação ripária para proteção, alimentação e reprodução (Castro 1999). As espécies de pequeno porte, encontradas em riachos e nas cabeceiras das drenagens, representam aproximadamente $50 \%$ do total de espécies de peixes descritas para água doce na América do Sul (Castro, 1999) e mais de $65 \%$ das espécies do Alto rio Paraná (Langeani et al. 2007). A importância de estudos de sistemática, evolução e biologia destas espécies foi destacada por Castro \& Menezes (1998) e Castro (1999), que consideraram a ampliação do conhecimento sobre a ictiofauna de cabeceiras o grande desafio da ictiologia sul-americana no século XXI. Atividades antrópicas, como desmatamento, o uso de fertilizantes e praguicidas na agricultura, trazem sérios riscos para este grupo de espécies, muitas delas sofrendo algum risco de extinção (Machado et al. 2008), algumas possivelmente antes mesmo de terem sido descritas (Böhlke et al., 1978).

O conhecimento da ictiofauna das cabeceiras do rio Tietê teve inicio com a descrição de Imparfinis piperatus e Nannoglanis bifasciatus por Eigenmann \& Norris (1900), com base em material coletado nas proximidades da cidade de São Paulo. Contudo, o atual conhecimento da ictiofauna da região é resultado principalmente de coletas realizadas pelo naturalista John D. Haseman, sob os auspícios do Carnegie Museum dos Estados Unidos na primeira década do século passado (Haseman \& Eigenmann 1911). O material coletado por Haseman gerou várias publicações com descrições de espécies do Alto rio Tietê (Eigenmann 1911, 1917, Ellis 1911). Descrições de espécies da região também foram feitas por Rudolph von Ihering (1905, 1907), que fez várias observações a respeito dos peixes do rio Tietê (von Ihering 1942). Durante a maior parte do século XX, exceção feita a publicações esparsas com descrições de novas espécies (Nichols 1919, Géry 1966, Travassos 1947, Britski \& Langeani, 1988), poucos estudos procuraram abordar aspectos da sistemática das espécies de peixes das cabeceiras do Tietê (Oliveira \& Britski, 2000). Langeani (1989) realizou o estudo mais completo a respeito da ictiofauna da região, identificando 42 espécies distribuídas em 11 famílias para todo Alto rio Tietê. Posteriormente, Giamas et al. (2004) e Silva (2006) realizaram levantamentos das espécies de peixes em áreas mais restritas, com novas citações de espécies. Aspectos da biologia e ecologia dos peixes das cabeceiras o rio Tietê foram abordados por Schröeder-Araújo (1980), Barrella \& Petrere (2003) e Esteves et al. (2008).

O presente estudo tem como objetivo descrever a composição taxonômica da ictiofauna de cabeceiras do rio Tietê, revisar e atualizar a nomenclatura das espécies e registrar novas espécies e novas citações para a região, com a documentação fotográfica dos ambientes amostrados e de espécimes representativos das espécies. Complementarmente, é apresentada uma chave de identificação para as espécies.

\section{1. Área de estudo e condições ambientais}

A região de cabeceiras do rio Tietê é uma subregião do Alto rio Tietê, com área aproximada de $1.889 \mathrm{~km}^{2}$, abrangendo os municípios de Biritiba-Mirim, Ferraz de Vasconcelos, Guararema, Itaquaquecetuba, Mogi das Cruzes, Poá, Salesópolis e Suzano. A drenagem de cabeceiras é formada pelo rio Tietê, da nascente até a divisa com Itaquaquecetuba, apresentando como principais tributários os rios Claro, Paraitinga, Biritiba-Mirim, Jundiaí e Taiaçupeba-Mirim (Figura 1). A região possui sete reservatórios artificiais projetados para produção de energia elétrica, abastecimento público e/ou controle de enchentes na grande São Paulo (Figura 1). O reservatório de Ponte Nova, formado pelo barramento do rio Tietê a $35 \mathrm{~km}$ de sua nascente, o reservatório de Jundiaí e o reservatório de Taiaçupeba, juntos inundam uma área de $64,85 \mathrm{~km}^{2}$ e os reservatórios de Biritiba-Mirim e de Paraitinga, respectivamente com área inundada de 9,24 e 6,43 km². Juntos, estes cinco reservatórios formam o Sistema Produtor Alto Tietê (SPAT) (São Paulo 2010, Solia et al. 2007). Os outros dois reservatórios de menor porte são o reservatório que barra o rio Tietê e abastece a Pequena Central Hidrelétrica (PCH ) de Salesópolis, inaugurada em 1913, e o reservatório de Ribeirão do Campo, que forma o sistema rio Claro de abastecimento de água.

Desde muito cedo, em 1700, existem relatos da exploração de ouro e ferro no estado de São Paulo, causando variações na cor e qualidade das águas do rio Tietê, enquanto a partir do século XVII a exploração da cultura de cana-de-açúcar foi responsável pelo primeiro ciclo de desmatamento das margens do rio Tietê e seus afluentes (Ferraz 2000). A região de cabeceiras do rio Tietê reúne municípios localizados em áreas de mananciais sobre proteção ambiental e a nascente do rio Tietê esta localizada em área parcialmente preservada pelo Departamento de Águas e Energia Elétrica (DAEE). A região encontra-se sujeita a forte pressão ambiental, decorrente de atividades relacionadas ao setor hortifrutigranjeiro e a indústria de papel-celulose, com forte impacto no meio ambiente, em especial sobre os recursos hídricos (Rocha 1991, Moraes et al. 2004). A região metropolitana de São Paulo apresenta uma grande demanda de água e os mananciais encontrados na região são muito importantes para o abastecimento de parte da Grande São Paulo (Tagnin \& Magalhães 2001). Especialmente entre as cabeceiras e a cidade de São Paulo, a intensa urbanização reduziu as áreas com formações vegetais nativas, substituídas por pastagens e culturas agrícolas diversas, com a deterioração da condição natural dos rios e da vegetação ciliar. No último relatório sobre a qualidade das águas interiores do estado de São Paulo (Cetesb 2009), o índice de qualidade de água para a proteção da vida aquática (IVA), apresenta avaliação regular na maioria dos pontos amostrados, sendo bom nos 


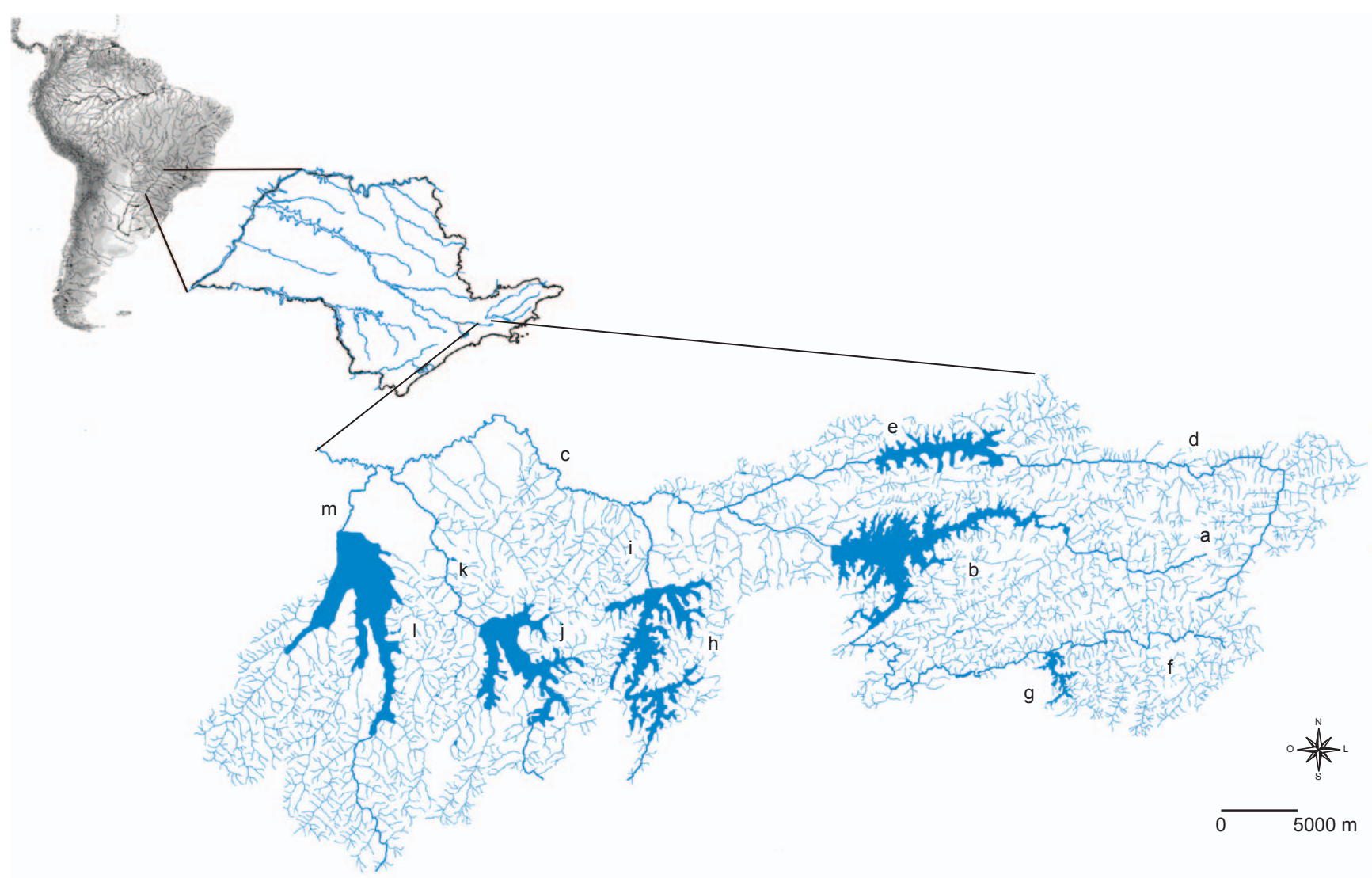

Figura 1. Bacia hidrográfica de cabeceiras do rio Tietê. a) Nascente do rio Tietê; b) reservatório de Ponte Nova; c) rio Tietê; d) rio Paraitinga; e) reservatório Paraitinga; f) rio Claro; g) reservatório de Ribeirão do Campo; h) reservatório de Biritiba-Mirim; i) rio Biritiba; j) reservatório Jundiaí; k) rio Jundiaí; l) reservatório de Taiçupeba; $\mathrm{m}$ ) rio Taiçupeba.

Figure 1. Hydrographic basin from the headboards of rio Tietê. a) Source of the rio Tietê; b) Ponte Nova reservoir; c) rio Tietê; d) rio Paraitinga; e) Paraitinga reservoir; f) rio Claro; g) Ribeirão do Campo reservoir; h) Biritiba-Mirim reservoir; i) rio Biritiba; j) Jundiaí reservoir; k) rio Jundiaí; l) Taiçupeba reservoir; m) rio Taiçupeba.

reservatórios de Taiaçupeba e Tanque Grande e péssimo em outros trechos do rio Tietê. Análises de metais pesados em sedimentos fluviais e grau de toxicidade ao longo do rio Tietê, mostram que nos três pontos amostrados da região de cabeceiras do rio Tietê, os níveis de contaminação foram considerados ausentes ou ausentes/ moderados em relação à maioria dos metais pesados, com exceção do $\mathrm{Zn}$, considerado como poluente moderado (Mortatti et al. 2010).

\section{Material e Métodos}

A lista de espécies foi elaborada com base no exame de material depositado nas coleções de peixes da UNESP de São José do rio Preto (DZSJRP) e do Museu de Zoologia da USP (MZUSP), além de material obtido através de novas coletas realizadas durante os anos de 2008-2009 pelos dois primeiros autores, material depositado nas coleções acima citadas e também nas coleções de peixes do Museu Nacional do Rio de Janeiro (MNRJ), da Universidade Estadual de Maringá (NUP) e do Laboratório de Biologia e Genética de Peixes da Universidade Estadual Paulista em Botucatu (LBP) (ver anexo I). O material testemunho listado reúne exemplares diretamente examinados pelos autores e/ou por especialistas dos respectivos grupos. A identidade das espécies (em parte) foi confirmada através de consultas a especialistas dos respectivos grupos taxonômicos (ver em Agradecimentos). As coletas foram realizadas em regiões com vegetação marginal bem conservada, trechos rurais e urbanos, além dos reservatórios artificiais (Figura 2). Nas Tabelas 1 e 2 e nas Figuras 3-5, a sequência das ordens, famílias e subfamílias encontradas nas cabeceiras do rio Tietê segue Buckup et al. (2007), os gêneros e espécies são apresentados em ordem alfabética dentro de cada família. Nas amostragens foram utilizadas combinações de métodos de captura de forma a serem obtidas amostras mais representativas da ictiofauna. Os métodos de coleta foram aqueles descritos por Malabarba \& Reis (1987), exceção feita à pesca elétrica (Mazzoni et al. 2000).

São consideradas espécies autóctones (nativas) aquelas que ocorrem naturalmente no Alto rio Paraná, espécies alóctones são aquelas descritas para outras bacias da região Neotropical e introduzidas sem quaisquer evidências de ocorrência natural no Alto rio Paraná e espécies exóticas todas aquelas de ocorrência natural em outros países e/ou continentes (Tabela 1). As espécies ameaçadas são aquelas incluídas no livro vermelho da fauna brasileira ameaçada de extinção (Rosa \& Lima 2008) e da fauna ameaçada de extinção no Estado de São Paulo (Oyakawa et al. 2009). As categorias de ameaça das espécies seguem Rosa \& Lima (2008). A definição das categorias de tamanho dos peixes, pequeno, médio e grande, segue Langeani et al. (2007).

\section{Resultados}

\section{Diversidade e origem da ictiofauna de cabeceiras do rio Tietê}

De acordo com o levantamento feito neste trabalho, as cabeceiras do rio Tietê abrigam 56 espécies de peixes, pertencentes a sete ordens, 16 famílias e 40 gêneros (Tabela 1, Figuras 3-5), 
aumentando significativamente o número de espécies assinaladas para região em levantamentos anteriores. Langeani (1989) registrou para região 38 espécies pertencentes a 11 famílias (42 espécies incluindo a drenagem do rio Pinheiros), Gimas et al. (2004) reconhecem 25 espécies, incluídas em 12 famílias e da Silva et al. (2006) identificaram 28 espécies, pertencentes a nove famílias. A combinação das espécies identificadas nos levantamentos anteriores permite reconhecer como primeiro registro para região as citações de:
Characidium cf. zebra, Scleromystax barbatus, Crenicichla britskii e Synbranchus cf. marmoratus (Tabela 1).

As espécies encontradas são habitantes típicos de rios e riachos de cabeceiras. A maioria das espécies $(71,4 \%)$ apresenta pequeno porte, menores de $200 \mathrm{~mm}$ de CP. Espécies de porte médio, entre 200-400 mm de CP, foram representadas por Oligosarcus paranensis, Hoplosternum cf. littorale, Hypostomus ancistroides, $H$. variipictus, Gymnotus pantherinus, Eigenmannia cf. virescens
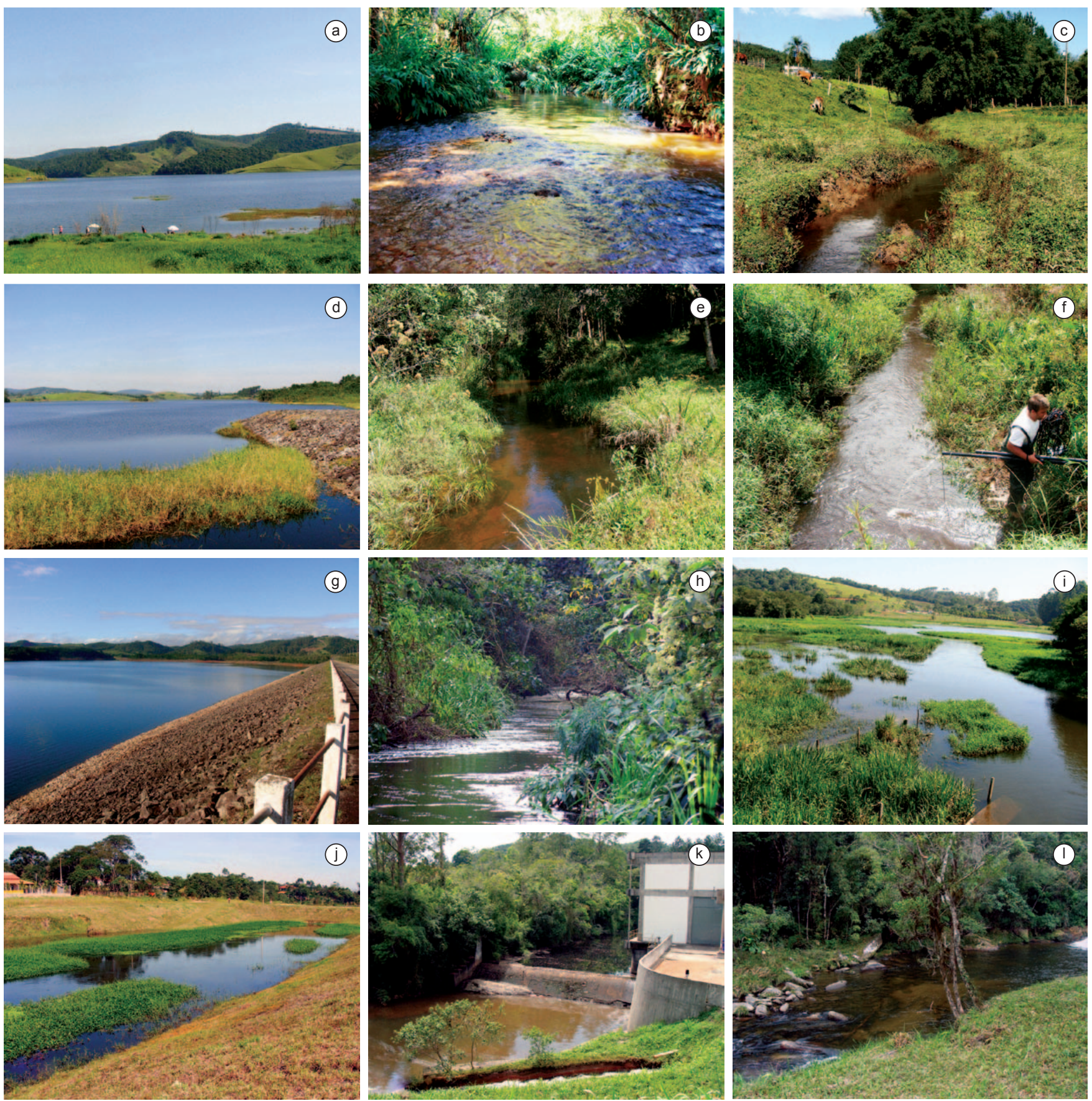

Figura 2. a) Reservatório de Paraitinga; b) rio Paraitinga em zona bem preservada; c) rio Paraitinga em zona rural; d) reservatório de Biritiba-Mirim; e) rio Biritiba em área preservada pelo DAEE; f) afluente do rio Biritiba em área preservada pelo DAEE; g) reservatório de Ponte Nova; h) rio Tietê abaixo do reservatório de Ponte Nova; i) rio Tietê em região rural de Biritiba-Mirim; j) canal de acesso ao reservatório Jundiaí; k) rio Claro próximo a sede da SABESP; 1) rio Claro na reserva da MZUSP.

Figure 2. a) Reservoir Paraitinga; b) preserved area of rio Paraitinga; c) rural area of rio Paraitinga; d) Biritiba-Mirim reservoir; e) preserved area of rio Biritiba; f) tributary of rio Biritiba in area preserved; g) Ponte Nova reservoir; h) rio Tietê downstream of the Ponte Nova reservoir; i) rio Tietê in the rural area in the Biritiba-Mirim town; j) inlet access channel Jundiaí reservoir; k) rio Claro near SABESP water treatment station; 1) rio Claro along the MZUSP field station. 
Tabela 1. Ictiofauna de cabeceiras do rio Tietê. A: espécies com algum tipo de ameaça segundo "Livro Vermelho da Fauna Basileira" e "Fauna Ameaçada de Extinção no Estado de São Paulo"; B: espécies endêmicas; C: espécies encontradas nas cabeceiras do rio Tietê e drenagens litorâneas; D: espécies introduzidas; E: novos registros.

Table 1. Ichthyofauna from the headwaters of the rio Tietê. A: endangered species according "Livro Vermelho da Fauna Brasileira" and "Fauna Ameaçada de Extinção no Estado de São Paulo"; B: endemic species; C: found in the headwaters of Tietê river and in the coastal drainages; D: introduced species; E: new records.

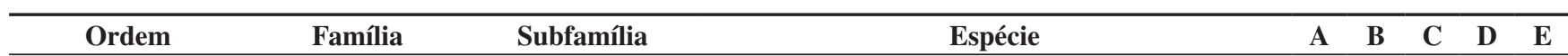

Clupeiformes

Clupeidae

Characiformes

Parodontidae

Curimatidae

Crenuchidae

Characidae

Cheirodontinae

Stervardiinae

Incertae sedis

Salmininae

Erythrinidae

Siluriformes

Trichomycteridae

Callichthyidae
Platanichthys platana (Regan 1917)

Apareiodon piracicabae (Eigenmann 1907)

Cyphocharax modestus (Fernández-Yépez 1948)

Cyphocharax sp.

Characidium oiticicai (Travassos 1967)

Characidium cf. zebra Eigenmann 1909

Characidium sp.

Serrapinnus notomelas (Eigenmann 1915)

Spintherobolus papilliferus Eigenmann 1911

Glandulocauda melanopleura (Ellis 1911)

Pseudocorynopoma heterandria Eigenmann 1914

Astyanax cf. altiparanae Garutti \& Britski 2000

Astyanax cf. fasciatus (Cuvier 1819)

Astyanax paranae Eigenmann 1914

Astyanax sp.

Coptobrycon bilineatus (Ellis 1911)

Hollandichthys multifasciatus (Eigenmann \& Norris 1900)

Hyphessobrycon cf. anisitsi (Eigenmann 1907)

Hyphessobrycon bifasciatus Ellis 1911

Hyphessobrycon duragenys Ellis 1911

Hyphessobrycon eques (Steindachner 1882)

Hyphessobrycon flammeus Myers 1924

Oligosarcus paranensis Menezes \& Gery 1983

Piabina anhembi da Silva \& Kaefer 2003

Salminus hilarii Valenciennes 1850

Hoplias cf. malabaricus (Bloch 1794)

Hoplias intermedius (Günther 1864)

Trichomycterus iheringi (Eigenmann 1917)

Trichomycterus paolence (Eigenmann 1917)

Corydoras aeneus (Gill 1858)

Corydoras nattereri Steindachner 1876 $\begin{array}{ccccc}- & - & - & - & - \\ X & X & - & - & -\end{array}$

$X-X--$

$X-X--$

$\begin{array}{ccccc}- & - & - & X & - \\ - & - & - & - & - \\ - & - & - & - & - \\ - & X & - & - & - \\ X & - & X & - & - \\ - & - & X & - & -\end{array}$

$\begin{array}{ccccc}- & - & - & - & - \\ - & - & - & - & - \\ X & - & X & - & - \\ - & - & - & X & - \\ X & - & X & - & - \\ - & - & - & - & - \\ - & X & - & - & -\end{array}$

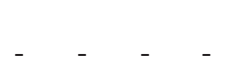

$\begin{array}{lllll}- & - & - & - & - \\ - & - & - & X & -\end{array}$ 
Tabela 1. Continuação...

Table 1. Continued...

\begin{tabular}{|c|c|c|c|c|c|c|c|c|}
\hline Ordem & Família & Subfamília & Espécie & $\mathbf{A}$ & B & $\mathbf{C}$ & D & $\mathbf{E}$ \\
\hline & & & Hoplosternum cf. littorale (Hancock 1828) & - & - & - & - & - \\
\hline & & & Scleromystax barbatus (Quoy \& Gaimard 1824) & - & - & $\mathrm{X}$ & - & $\mathrm{X}$ \\
\hline
\end{tabular}

Loricariidae

Neoplecostominae

\begin{tabular}{|c|c|c|c|c|c|}
\hline & Neoplecostomus paranensis Langeani 1990 & $\mathrm{X}$ & - & - & - \\
\hline & Pareiorhina sp. & - & $\mathrm{X}$ & - & - \\
\hline \multicolumn{6}{|c|}{ Hypoptopomatinae } \\
\hline & Hisonotus depressicauda (Miranda-Ribeiro 1918) & - & - & - & - \\
\hline & Pseudotocinclus tietensis (Ihering 1907) & $\mathrm{X}$ & - & $\mathrm{X}$ & - \\
\hline \multicolumn{6}{|l|}{ Hypostominae } \\
\hline & Hypostomus ancistroides (Ihering 1911) & - & - & - & - \\
\hline & Hypostomus variipictus (Ihering 1911) & - & - & - & - \\
\hline & Cetopsorhamdia iheringi Schubart \& Gomes 1959 & - & - & - & - \\
\hline & Imparfinis piperatus Eigenmann \& Norris 1900 & - & - & - & - \\
\hline & Pimelodella meeki Eigenmann 1910 & - & $\mathrm{X}$ & - & - \\
\hline & Rhamdia cf. quelen (Quoy \& Gaimard 1824) & - & - & - & - \\
\hline & Taunayia bifasciata (Eigenmann \& Norris 1900) & $X$ & - & $\mathrm{X}$ & - \\
\hline
\end{tabular}

Gymnotiformes

Gymnotidae

Sternopygidae

Gymnotus pantherinus (Steindachner 1908)

Gymnotus sylvius Albert \& Fernandes-Matioli 1999

$-\quad \mathrm{X}-\mathrm{-}$

Eigenmannia cf. virescens (Valenciennes 1836)

Cyprinodontiformes

Poeciliidae

Phalloceros harpagos Lucinda 2008

Phalloceros reisi Lucinda 2008

Perciformes

Cichlidae

Australoheros sp.

Crenicichla britskii Kullander 1982

Geophagus brasiliensis (Quoy \& Gaimard 1824)

Oreochromis niloticus (Linnaeus 1758)

Tilapia rendalli (Boulenger 1897)

Centrarchidae

Micropterus salmoides (Lacepède 1802)

Synbranchiformes

Synbranchidae

Synbranchus cf. marmoratus Bloch 1795

$\mathrm{X}$

e Geophagus brasiliensis. Espécies de grande porte, maiores de $400 \mathrm{~mm}$ de CP, foram representadas por Salminus hilarii, Hoplias cf. malabaricus, H. intermedius, Rhamdia cf. quelen, Gymnotus sylvius, Oreochromis niloticus, Tilapia rendalli, Micropterus salmoides e Synbranchus cf. marmoratus.

Dentre as espécies autóctones, 13 apresentam uma ampla distribuição e também são encontradas fora da bacia do Alto rio Paraná $(23,2 \%)$, cinco ocorrem na bacia do Alto rio Paraná e drenagens litorâneas $(8,9 \%)$, dez ocorrem exclusivamente no Alto rio Paraná (17,9\%), 13 são encontradas nas cabeceiras do Tietê e drenagens litorâneas $(23,2 \%)$ e oito são encontradas exclusivamente nas cabeceiras do Alto rio Tietê (14,3\%), alem de outras sete espécies exóticas e alóctones (Tabela 1).

\section{Espécies novas e a nomenclatura das espécies reconhecidas}

Análises morfológicas adicionais de séries amostrais maiores e análises complementares de DNA (em parte dos casos), permitem o reconhecimento de pelo menos cinco espécies novas pertencentes aos gêneros Cyphocharax, Characidium, Astyanax, Pareiorhina e Australoheros (Tabela 1). Dentre essas espécies, algumas nunca haviam sido referidas para as cabeceiras do rio Tietê, 
Tabela 2. Distribuição das espécies de peixes registradas nas cabeceiras do rio Tietê.

Table 2. Distribution of the fish species recorded in the headwaters of the Tietê river.

\begin{tabular}{|c|c|c|c|c|c|c|c|c|c|c|}
\hline \multirow[t]{2}{*}{ Espéceis } & \multicolumn{5}{|c|}{ Drenagens principais } & \multicolumn{5}{|c|}{ Reservatórios } \\
\hline & Biritiba & Claro & Jundiai & Paraitinga & Tietê & $\begin{array}{c}\text { Biritiba } \\
\text { Mirim }\end{array}$ & Jundiaí & Paraitinga & $\begin{array}{l}\text { Ponte } \\
\text { Nova }\end{array}$ & Taiaçupeba \\
\hline Platanichthys platana & - & - & - & - & - & - & - & - & - & $\mathrm{X}$ \\
\hline Apareiodon piracicabae & - & - & - & - & $\mathrm{X}$ & - & $\mathrm{X}$ & - & - & $\mathrm{X}$ \\
\hline Cyphocharax modestus & - & - & - & - & $\mathrm{X}$ & - & - & - & $\mathrm{X}$ & - \\
\hline Cyphocharax sp. & - & - & - & - & $X$ & - & - & - & $\mathrm{X}$ & - \\
\hline Characidium oiticicai & - & $\mathrm{X}$ & - & - & - & - & - & - & - & - \\
\hline Characidium cf. zebra & - & - & - & $\mathrm{X}$ & - & - & - & - & - & - \\
\hline Characidium sp. & - & - & - & $\mathrm{X}$ & $\mathrm{X}$ & - & - & - & - & - \\
\hline Serrapinnus notomelas & - & - & - & - & $\mathrm{X}$ & - & $\mathrm{X}$ & - & - & $\mathrm{X}$ \\
\hline Spintherobolus papilliferus & - & $\mathrm{X}$ & - & - & - & - & - & - & - & - \\
\hline Glandulocauda melanopleura & - & $\mathrm{X}$ & - & - & - & - & - & - & - & - \\
\hline Pseudocorynopoma heterandria & $\mathrm{X}$ & - & - & - & $\mathrm{X}$ & - & - & - & $\mathrm{X}$ & $\mathrm{X}$ \\
\hline Astyanax cf. altiparanae & - & - & - & $\mathrm{X}$ & $\mathrm{X}$ & - & - & - & $\mathrm{X}$ & $\mathrm{X}$ \\
\hline Astayanax cf. fasciatus & - & - & - & - & $\mathrm{X}$ & - & - & - & $\mathrm{X}$ & - \\
\hline Astyanax paranae & - & $\mathrm{X}$ & - & - & $\mathrm{X}$ & - & - & - & $\mathrm{X}$ & - \\
\hline Astyanax sp. & - & $X$ & - & - & $\mathrm{X}$ & - & - & - & $\mathrm{X}$ & $\mathrm{X}$ \\
\hline Coptobrycon bilineatus & - & - & - & - & $\mathrm{X}$ & - & - & - & - & - \\
\hline Hollandichthys multifasciatus & $\mathrm{X}$ & - & - & - & $\mathrm{X}$ & - & - & - & - & - \\
\hline Hyphessobrycon cf. anisitsi & - & $\mathrm{X}$ & - & - & - & - & - & - & - & - \\
\hline Hyphessobrycon bifasciatus & - & - & - & $\mathrm{X}$ & $\mathrm{X}$ & - & $\mathrm{X}$ & - & $\mathrm{X}$ & $\mathrm{X}$ \\
\hline Hyphessobrycon duragenys & - & - & - & - & $\mathrm{X}$ & - & - & - & - & - \\
\hline Hyphessobrycon eques & - & - & - & - & - & - & $\mathrm{X}$ & - & - & $\mathrm{X}$ \\
\hline Hyphessobrycon flammeus & - & - & - & - & $\mathrm{X}$ & - & - & - & - & - \\
\hline Oligosarcus paranensis & - & $\mathrm{X}$ & - & $\mathrm{X}$ & $\mathrm{X}$ & - & - & - & $\mathrm{X}$ & - \\
\hline Piabina anhembi & - & - & - & - & - & - & - & - & - & - \\
\hline Salminus hilarii & - & - & - & - & $\mathrm{X}$ & - & - & - & - & - \\
\hline Hoplias intermedius & - & - & - & - & - & - & - & - & $\mathrm{X}$ & - \\
\hline Hoplias cf. malabaricus & - & $\mathrm{X}$ & - & $\mathrm{X}$ & $\mathrm{X}$ & - & - & - & $\mathrm{X}$ & - \\
\hline Trichomycterus iheringi & - & $\mathrm{X}$ & - & $\mathrm{X}$ & $\mathrm{X}$ & - & - & - & - & - \\
\hline Trichomycterus paolence & - & $\mathrm{X}$ & - & - & - & - & - & - & - & - \\
\hline Corydoras aeneus & $X$ & - & - & - & $\mathrm{X}$ & - & - & - & - & - \\
\hline Corydoras nattereri & - & - & - & $\mathrm{X}$ & $\mathrm{X}$ & - & $\mathrm{X}$ & - & - & $\mathrm{X}$ \\
\hline Hoplosternum cf. littorale & - & - & - & - & - & - & - & - & $\mathrm{X}$ & - \\
\hline Scleromystax barbatus & $\mathrm{X}$ & - & - & - & - & - & - & - & - & - \\
\hline Neoplecostomus paranensis & - & $\mathrm{X}$ & - & $\mathrm{X}$ & $\mathrm{X}$ & - & - & - & - & $\mathrm{X}$ \\
\hline Pareiorhina & - & $X$ & - & - & - & - & - & - & - & - \\
\hline Hisonotus depressicauda & $\mathrm{X}$ & - & - & $\mathrm{X}$ & - & - & - & - & - & - \\
\hline Pseudotocinclus tietensis & $\mathrm{X}$ & - & - & $\mathrm{X}$ & - & - & - & - & - & - \\
\hline Hypostomus ancistroides & - & - & - & - & $\mathrm{X}$ & - & - & - & - & - \\
\hline Hypostomus variipictus & - & - & - & - & - & $\mathrm{X}$ & - & - & $\mathrm{X}$ & - \\
\hline Cetopsorhamdia iheringi & $\mathrm{X}$ & $\mathrm{X}$ & - & $\mathrm{X}$ & - & - & - & - & - & - \\
\hline Imparfinis piperatus & $X$ & - & - & $\mathrm{X}$ & $X$ & - & - & - & - & - \\
\hline Pimelodella meeki & - & - & - & $\mathrm{X}$ & $\mathrm{X}$ & - & - & - & $\mathrm{X}$ & - \\
\hline Rhamdia cf. quelen & - & $\mathrm{X}$ & - & - & $X$ & - & - & - & $\mathrm{X}$ & - \\
\hline Taunayia bifasciata & - & $\mathrm{X}$ & - & - & - & - & - & - & - & - \\
\hline Gymnotus pantherinus & - & $\mathrm{X}$ & - & $\mathrm{X}$ & $X$ & - & $\mathrm{X}$ & - & - & - \\
\hline Gymnotus sylvius & - & - & - & - & $\mathrm{X}$ & - & $\mathrm{X}$ & - & - & - \\
\hline Eigenmannia cf. virescens & - & - & - & - & $\mathrm{X}$ & - & - & - & $\mathrm{X}$ & - \\
\hline Phalloceros harpagos & - & - & - & - & $\mathrm{X}$ & - & - & - & - & - \\
\hline Phalloceros reisi & - & $X$ & - & $\mathrm{X}$ & $\mathrm{X}$ & - & - & - & - & - \\
\hline Australoheros sp. & - & - & - & $\mathrm{X}$ & $X$ & - & - & - & $X$ & - \\
\hline Crenicichla britskii & $\mathrm{X}$ & - & - & - & - & - & - & - & - & $\mathrm{X}$ \\
\hline Geophagus brasiliensis & $\mathrm{X}$ & - & - & $\mathrm{X}$ & $\mathrm{X}$ & - & $\mathrm{X}$ & - & $\mathrm{X}$ & $\mathrm{X}$ \\
\hline Oreochromis niloticus & - & - & - & - & - & - & $\mathrm{X}$ & - & $\mathrm{X}$ & $\mathrm{X}$ \\
\hline Tilapia rendalli & - & - & - & - & - & - & - & - & $\mathrm{X}$ & $\mathrm{X}$ \\
\hline Micropterus salmoides & - & - & - & - & - & - & - & - & $\mathrm{X}$ & - \\
\hline Synbranchus cf. marmoratus & - & - & - & - & $\mathrm{X}$ & - & - & - & - & - \\
\hline
\end{tabular}




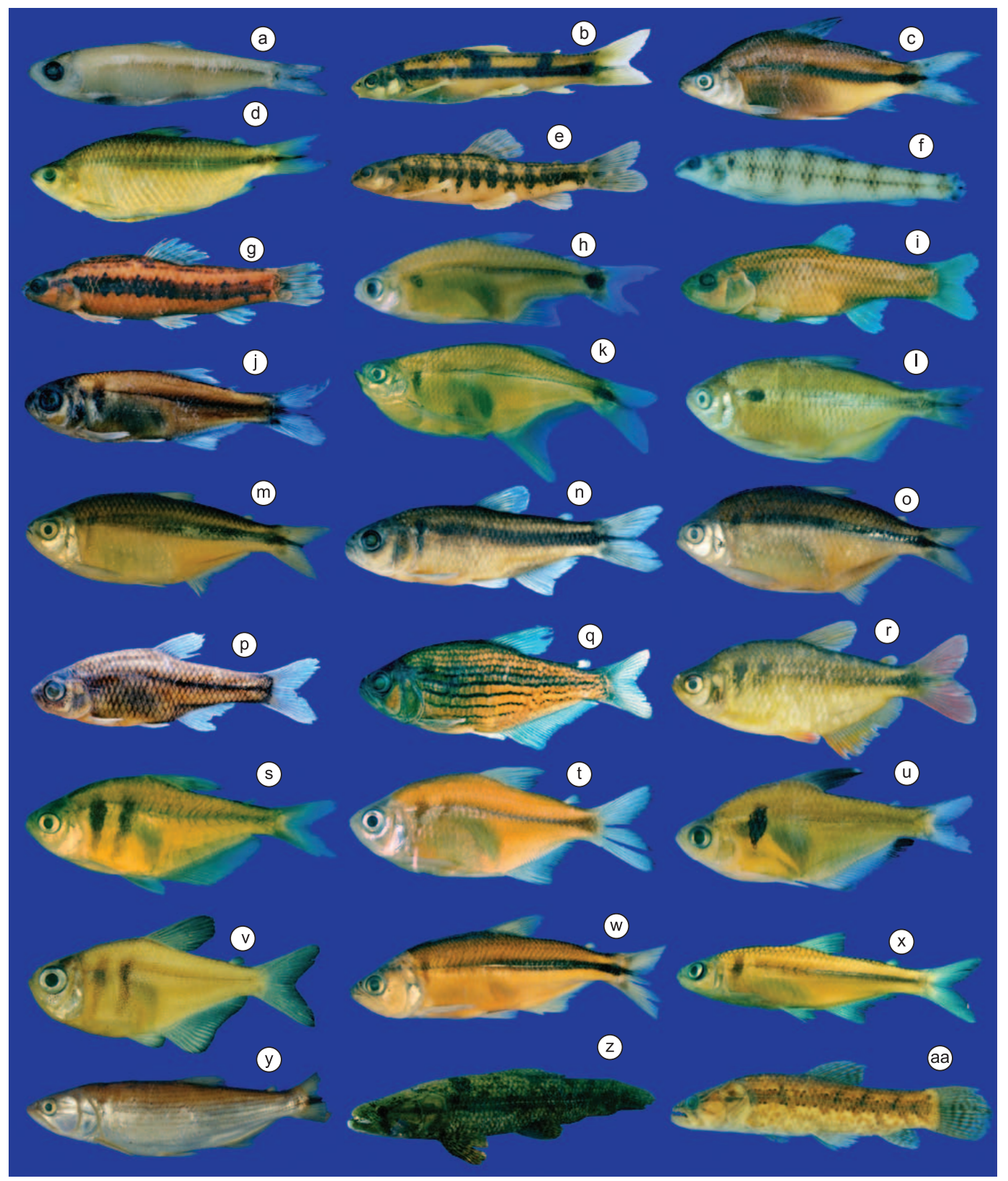

Figura 3. Espécies de peixes de cabeceiras do rio Tietê. Clupeiformes: a) Platanichthys platana, DZSJRP 12718, 56,4 mm CP. Characiformes: b) Apareiodon piracicabae, NUP 7028, 81,9 mm CP; c) Cyphocharax modestus, DZSJRP 12847, 69,4 mm CP; d) Cyphocharax sp., exemplar não registrado, 155,2 mm CP; e) Characidium oiticicai, DZSJRP 8329, 45,6 mm CP; f) Characidium cf. zebra, DZSJRP 11423, 54,7 mm CP; g) Characidium sp., DZSJRP 6933, 47,5 mm CP; h) Serrapinnus notomelas, DZSJRP 12725, 26,9 mm CP; i) Spintherobolus papilliferus, DZSJRP 2244, 47,7 mm CP; j) Glandulocauda melanopleura, DZSJRP 6613, 28,8 mm CP; k) Pseudocorynopoma heterandria, DZSJRP 11427, 50,1 mm CP; 1) Astyanax cf. altiparanae, exemplar não registrado, 78,0 mm CP; m) Astayanax cf. fasciatus, DZSJRP 12834, 125,2 mm CP; n) Astyanax paranae, DZSJRP 6629, 61,4 mm CP; o) Astyanax sp., DZSJRP 12833, 93,6 mm CP; p) Coptobrycon bilineatus, DZSJRP 6610, 29,1 mm CP; q) Hollandichthys multifasciatus, DZSJRP 5724, 50,6 mm CP; r) Hyphessobrycon cf. anisitsi, DZSJRP 2256, 59,2 mm CP; s) Hyphessobrycon bifasciatus, DZSJRP 12818, 44,8 mm CP; t) Hyphessobrycon duragenys, MZUSP 42325, 52,1 mm CP; u) Hyphessobrycon eques, DZSJRP 12850, 34,4 mm CP; v) Hyphessobrycon flammeus, MZUSP 102799, 21,6 mm CP; w) Oligosarcus paranensis, DZSJRP 12832, 129,3 mm CP; x) Piabina anhembi, MZUSP 59144, 58,7 mm CP; y) Salminus hilarii, DZSJRP 12824, 160,2 mm CP; z) Hoplias intermedius, exemplar não preservado; (aa) Hoplias cf. malabaricus, DZSJRP 12827, 104,4 mm CP.

Figure 3. Fish species of the headwater of rio Tietê. Clupeiformes: a) Platanichthys platana, DZSJRP 12718, 56,4 mm CP. Characiformes: b) Apareiodon piracicabae, NUP 7028, 81,9 mm CP; c) Cyphocharax modestus, DZSJRP 12847, 69,4 mm CP; d) Cyphocharax sp., exemplar não registrado, 155,2 mm CP; e) Characidium oiticicai, DZSJRP 8329, 45,6 mm CP; f) Characidium cf. zebra, DZSJRP 11423, 54,7 mm CP; g) Characidium sp., DZSJRP 6933, 47,5 mm CP; h) Serrapinnus notomelas, DZSJRP 12725, 26,9 mm CP; i) Spintherobolus papilliferus, DZSJRP 2244, 47,7 mm CP; j) Glandulocauda melanopleura, DZSJRP 6613, 28,8 mm CP; k) Pseudocorynopoma heterandria, DZSJRP 11427, 50,1 mm CP; 1) Astyanax cf. altiparanae, exemplar não registrado, 78,0 mm CP; m) Astayanax cf. fasciatus, DZSJRP 12834, 125,2 mm CP; n) Astyanax paranae, DZSJRP 6629, 61,4 mm CP; o) Astyanax sp., DZSJRP 12833, 93,6 mm CP; p) Coptobrycon bilineatus, DZSJRP 6610, 29,1 mm CP; q) Hollandichthys multifasciatus, DZSJRP 5724, 50,6 mm CP; r) Hyphessobrycon cf. anisitsi, DZSJRP 2256, 59,2 mm CP; s) Hyphessobrycon bifasciatus, DZSJRP 12818, 44,8 mm CP; t) Hyphessobrycon duragenys, MZUSP 42325, 52,1 mm CP; u) Hyphessobrycon eques, DZSJRP 12850, 34,4 mm CP; v) Hyphessobrycon flammeus, MZUSP 102799, 21,6 mm CP; w) Oligosarcus paranensis, DZSJRP 12832, 129,3 mm CP; x) Piabina anhembi, MZUSP 59144, 58,7 mm CP; y) Salminus hilarii, DZSJRP 12824, 160,2 mm CP; z) Hoplias intermedius, exemplar não preservado; (aa) Hoplias cf. malabaricus, DZSJRP 12827, 104,4 mm CP. 
como Characidium sp., ou foram tidas como espécies com ampla distribuição, como Astyanax sp. (= Astyanax eigenmanniorum (Cope 1894), sensu Langeani (1989), Giamas et al. (2004) e da Silva et al. (2006), Australoheros sp. (= Cichlasoma facetum (Jenyns 1842), sensu Langeani (1989) e da Silva et al. (2006). Outras duas espécies pertencentes aos gêneros Pareiorhina e Cyphocharax, foram anteriormente identificadas como espécies novas por Langeani (1989). È possível que revisões taxonômicas das espécies com ampla distribuição, como Astyanax cf. fasciatus, Hyphessobrycon cf. anisitsi, Characidium cf. zebra, Eigenmannia cf. virescens, Hoplias cf. malabaricus, Hoplosternum cf. littorale, Rhamdia cf. quelen e Synbranchus cf. marmoratus, possam confirmar a existência de novas espécies, como demonstrado por Garutti \& Britski (2000) e Vari \& Castro (2007) respectivamente para Astyanax altiparanae e A. bockmanni Vari \& Castro 2007, descritas para o Alto Paraná, onde as mesmas foram anteriormente respectivamente referidas como Astyanax bimaculatus (Linnaeus 1758) e Astyanax eigenmanniorum.

A nomenclatura aqui adotada muitas vezes difere daquela empregada em estudos anteriores: um resumo das diferenças nomenclaturais encontradas na literatura recente é apresentada no Anexo I. Hyphessobrycon reticulatus Ellis 1911, descrita com base em material-tipo de Mogi das Cruzes e citada para região por da Silva et al. (2006), não foi identificada no material examinado, enquanto possíveis espécies novas citadas para região, Astyanax sp. [sensu Langeani (1989)], Gênero n. espécie. n [= Cheirodontinae sensu da Silva et al. (2006)], Oligosarcus sp. [sensu Gimas et al. (2004)], Hypostomus sp. [sensu Gimas et al. (2004) e da Silva et al. (2006)], não foram observadas.

\section{Estado atual da conservação das espécies}

A região têm sofrido com alterações das condições ambientais, como a mudança do sistema de lótico para lêntico decorrente do represamento dos principais rios da região e a substituição da vegetação nativa pelo eucalipto (Eucaliptus spp.) e/ou atividades agrícolas diversas (Cetra \& Petrere Junior 2007). Como consequiência, as espécies de peixes autóctones, a maior parte delas adaptadas a ambientes lóticos, têm sofrido redução de seus hábitats, enquanto espécies alóctones ou exóticas, muitas com grande capacidade de adaptação, têm se beneficiado e proliferado nas porções represadas (Tabela 2). Das espécies autóctones, pelos menos 23 delas, não foram encontradas nos reservatórios artificiais (Tabela 2). Estas espécies possuem pequeno porte e estão diretamente relacionadas com ambientes de corredeiras com boa oxigenação e rica vegetação ciliar.

A introdução de espécies pelo homem é outro fator de impacto sobre a ictiofauna nativa (Welcomme 1988, Leprieur et al. 2008). Na região de cabeceiras da bacia do Alto rio Tietê são encontradas pelo menos três espécies exóticas estabelecidas: Oreochromis niloticus, Micropterus salmoides e Tilapia rendalli, introduzidas após a construção da barragem de Ponte Nova na década de 70 com objetivo de incrementar a pesca esportiva. Dentre as espécies alóctones estabelecidas, podemos citar: Hyphessobrycon eques, que é uma espécie com interesse comercial para o aquarismo; Astyanax cf. altiparanae provavelmente oriunda da piscicultura da CESP Paraibuna (segundo depoimento de pescadores antigos, a espécie não ocorria na região antes da década de 90); Hoplias intermedius, com registros somente para o reservatório de Ponte Nova e Platanichthys platana, as duas ultimas sem um histórico da possível origem de introdução. Das espécies introduzidas, exceção feita a Astyanax cf. altiparanae, todas são encontradas exclusivamente nos reservatórios artificiais da região (Tabela 2).
Na região de cabeceiras do rio Tietê ocorrem dez espécies que apresentam algum risco de extinção segundo as listas da fauna ameaçada de extinção da fauna brasileira (Rosa \& Lima 2008) e do estado de São Paulo (Oyakawa et al. 2009). Destas, quatro foram capturadas em coletas realizadas: Pseudocorynopoma heterandria (vulnerável) e Hyphessobrycon flammeus (em perigo) foram encontradas com relativa frequiência no rio Tietê, na zona rural de Biritiba Mirim e nos reservatórios de Jundiaí e Taiçupeba, a segunda também relativamente comum em lojas de aquário da região; Neoplecostomus paranensis (vulnerável) foi capturada com relativa freqüência no rio Paraitinga; enquanto Pseudotocinclus tietensis (vulnerável) foi capturada no rio Paraitinga e rio Biritiba. As espécies Hyphessobrycon duragenys (em perigo), conhecida para região de cabeceiras somente através do exemplar-tipo, Spintherobolus papilliferus (criticamente em perigo), Coptobrycon bilineatus (em perigo), Glandulocauda melanopleura (vulnerável), Trichomycterus paolence (em perigo) e Taunayia bifasciata (vulneral) não foram observadas nas coletas realizadas; entretanto as quatro ultimas tem sido capturadas no rio Itatinga, drenagem litorânea pertencente a bacia do rio Itapanhaú, que compartilha uma história biogeográfica em comum com a bacia de cabeceira do rio Tietê (Serra et al. 2007).

\section{Discussão}

As cabeceiras do rio Tietê têm composição ictiofaunística bastante peculiar e distinta daquela encontrada no restante do Alto rio Paraná (Castro et al 2003, 2004), com espécies não descritas e outras apresentando dúvidas em relação à identidade taxonômica. A ictiofauna da região é caracterizada por um grande número de espécies endêmicas e muita similaridade com bacias hidrográficas litorâneas vizinhas (Serra et al 2007, Mattox \& Iglesias, 2010), corroborando a ocorrência pretérita de fenômenos de captura de cabeceiras dos rios da região e drenagens da Serra do Mar, como proposto por Ribeiro (2006), Ribeiro et al. (2006), Serra et al. (2007). A conspecifidade das espécies encontradas nas cabeceiras do rio Tietê e drenagens litorâneas vizinhas necessita confirmação, como demonstrado para Trichomycterus iheringi por Silva et al. (2010). Espécies com ampla distribuição na região Neotropical, aqui referidas como “cf.", também necessitam confirmação de sua identidade taxonômica.

Nogueira et al. (2010) mostram que a avaliação da diversidade de peixes de água doce tem sido negligenciada na maioria dos levantamentos, sustentando políticas equivocadas de estabelecimento de áreas prioritárias de conservação com base na presença de espécies endêmicas e no grau de ameaça das espécies. As cabeceiras do rio Tietê tem sofrido forte impacto decorrente da interferência humana e a proximidade com a região metropolitana da grande São Paulo devido o represamento dos rios, substituição da vegetação ciliar e introdução de espécies, como conseqüência, são encontradas na região dez espécies de peixes que mostram algum risco de extinção (Rosa \& Lima 2008, Oyakawa et al. 2009). Apesar disso, as cabeceiras do rio Tietê possuem áreas com vegetação ciliar em bom estado de conservação, como na Estação Biológica de Boracéia (dentro da área da SABESP), a porção superior do rio Biritiba, acima do reservatório de Biritiba Mirim, e a porção superior do rio Paraitinga (dentro dos limites da fazenda da Companhia Suzano Papel e Celulose). A conservação destas áreas é fundamental para preservação das espécies de peixes que outrora eram encontradas em todo Alto rio Tietê, incluindo a região metropolitana da cidade de São Paulo, algumas delas endêmicas e/ou ainda não descritas. Neste sentido, os resultados apresentados podem servir para subsidiar medidas de conservação e manejo desta importante região do estado de São Paulo, evitando a degradação de áreas preservadas e a conservação de espécies únicas de nossa ictiofauna. 


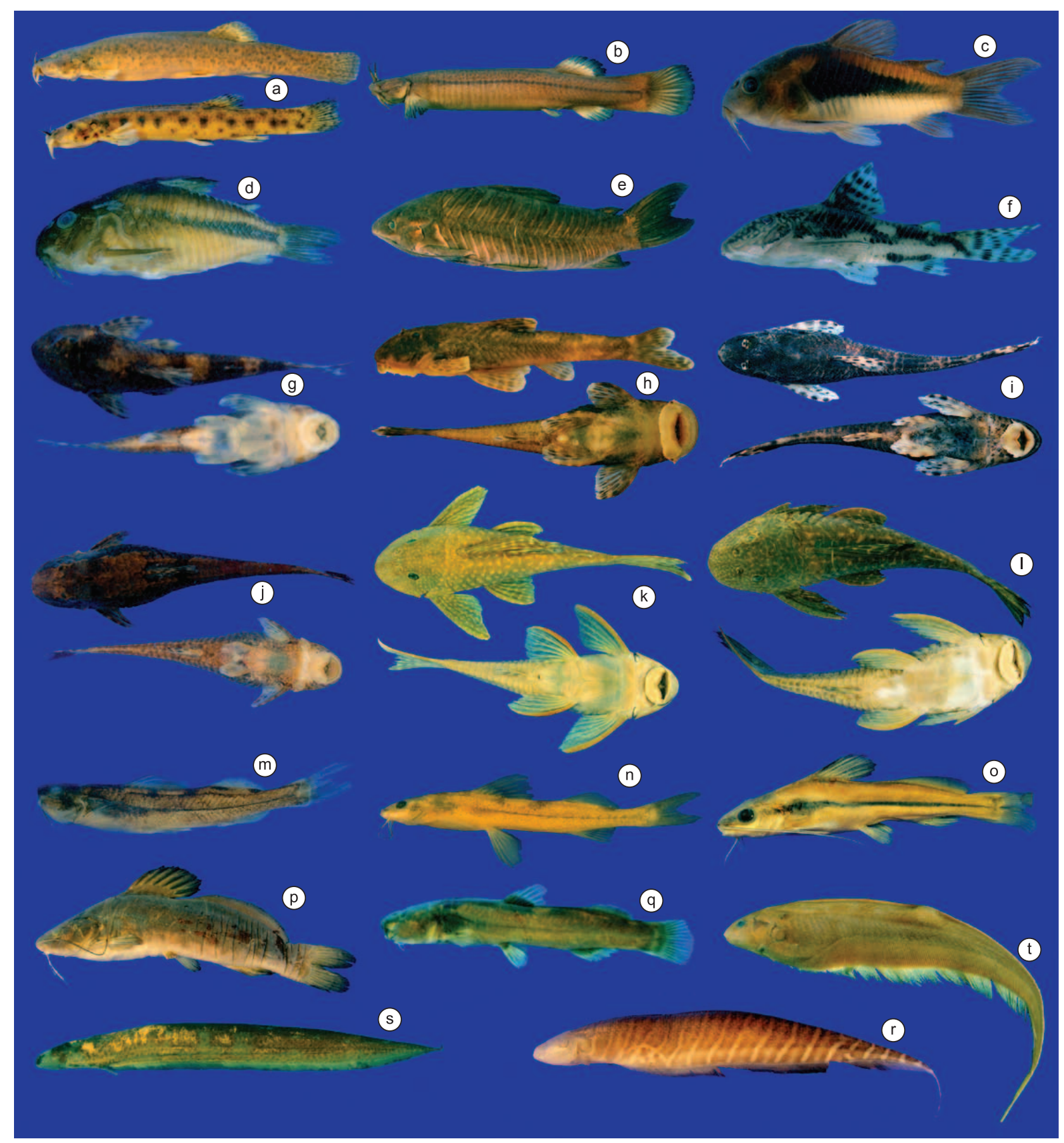

Figura 4. Espécies de peixes de cabeceiras do rio Tietê. Siluriformes: a) Trichomycterus iheringi, jovem DZSJRP 12334, 49,4 mm CP e adulto DZSJRP 12338, 101,0 mm CP; b) Trichomycterus paolence, MZUSP 99698, 97,3 mm CP; c) Corydoras aeneus, DZSJRP 12810, 38,5 mm CP; d) Corydoras nattereri, DZSJRP 12848, 34,3 mm CP; e) Hoplosternum cf. littorale, DZSJRP 12849, 161,3 mm CP; f) Scleromystax barbatus, MNRJ 36792, 44,96 mm CP; g) Neoplecostomus paranensis, DZSJRP 11420, 46,5 mm CP; h) Pareiorhina sp., DZSJRP 8333, 65,5 mm CP em vista lateral e DZSJRP 8338, 59,0 mm CP em vista ventral; i) Hisonotus depressicauda, DZSJRP 11422, 34,9 mm CP; j) Pseudotocinclus tietensis, DZSJRP 12841, 56,6 mm CP; k) Hypostomus ancistroides exemplar não registrado, 162,5 mm CP; 1) Hypostomus variipictus, DZSJRP 12830, 145,8 mm CP; m) Cetopsorhamdia iheringi, DZSJRP 12808, 59,4 mm CP; n) Imparfinis piperatus, DZSJRP 12851, 59,6 mm CP; o) Pimelodella meeki, DZSJRP 12845, 68,9 mm CP; p) Rhamdia cf. quelen, DZSJRP 12813, 183,0 mm CP; q) Taunayia bifasciata, exemplar não registrado, 55,4 mm CP. Gymnotiformes: r) Gymnotus sylvius, DZSJRP 12821, 125,1 mm CP; s) Gymnotus pantherinus, DZSJRP 12828, 105,3 mm CP; t) Eigenmannia cf. virescens, MZUSP 22748, 190,0 mm CP.

Figure 4. Fish species of the headwater of rio Tietê. Siluriformes: a) Trichomycterus iheringi, jovem DZSJRP 12334, 49,4 mm CP e adulto DZSJRP 12338, 101,0 mm CP; b) Trichomycterus paolence, MZUSP 99698, 97,3 mm CP; c) Corydoras aeneus, DZSJRP 12810, 38,5 mm CP; d) Corydoras nattereri, DZSJRP 12848, 34,3 mm CP; e) Hoplosternum cf. littorale, DZSJRP 12849, 161,3 mm CP; f) Scleromystax barbatus, MNRJ 36792, 44,96 mm CP; g) Neoplecostomus paranensis, DZSJRP 11420, 46,5 mm CP; h) Pareiorhina sp., DZSJRP 8333, 65,5 mm CP em vista lateral e DZSJRP 8338, 59,0 mm CP em vista ventral; i) Hisonotus depressicauda, DZSJRP 11422, 34,9 mm CP; j) Pseudotocinclus tietensis, DZSJRP 12841, 56,6 mm CP; k) Hypostomus ancistroides exemplar não registrado, 162,5 mm CP; 1) Hypostomus variipictus, DZSJRP 12830, 145,8 mm CP; m) Cetopsorhamdia iheringi, DZSJRP 12808, 59,4 mm CP; n) Imparfinis piperatus, DZSJRP 12851, 59,6 mm CP; o) Pimelodella meeki, DZSJRP 12845, 68,9 mm CP; p) Rhamdia cf. quelen, DZSJRP 12813, 183,0 mm CP; q) Taunayia bifasciata, exemplar não registrado, 55,4 mm CP. Gymnotiformes: r) Gymnotus sylvius, DZSJRP 12821, 125,1 mm CP; s) Gymnotus pantherinus, DZSJRP 12828, 105,3 mm CP; t) Eigenmannia cf. virescens, MZUSP 22748, 190,0 mm CP. 


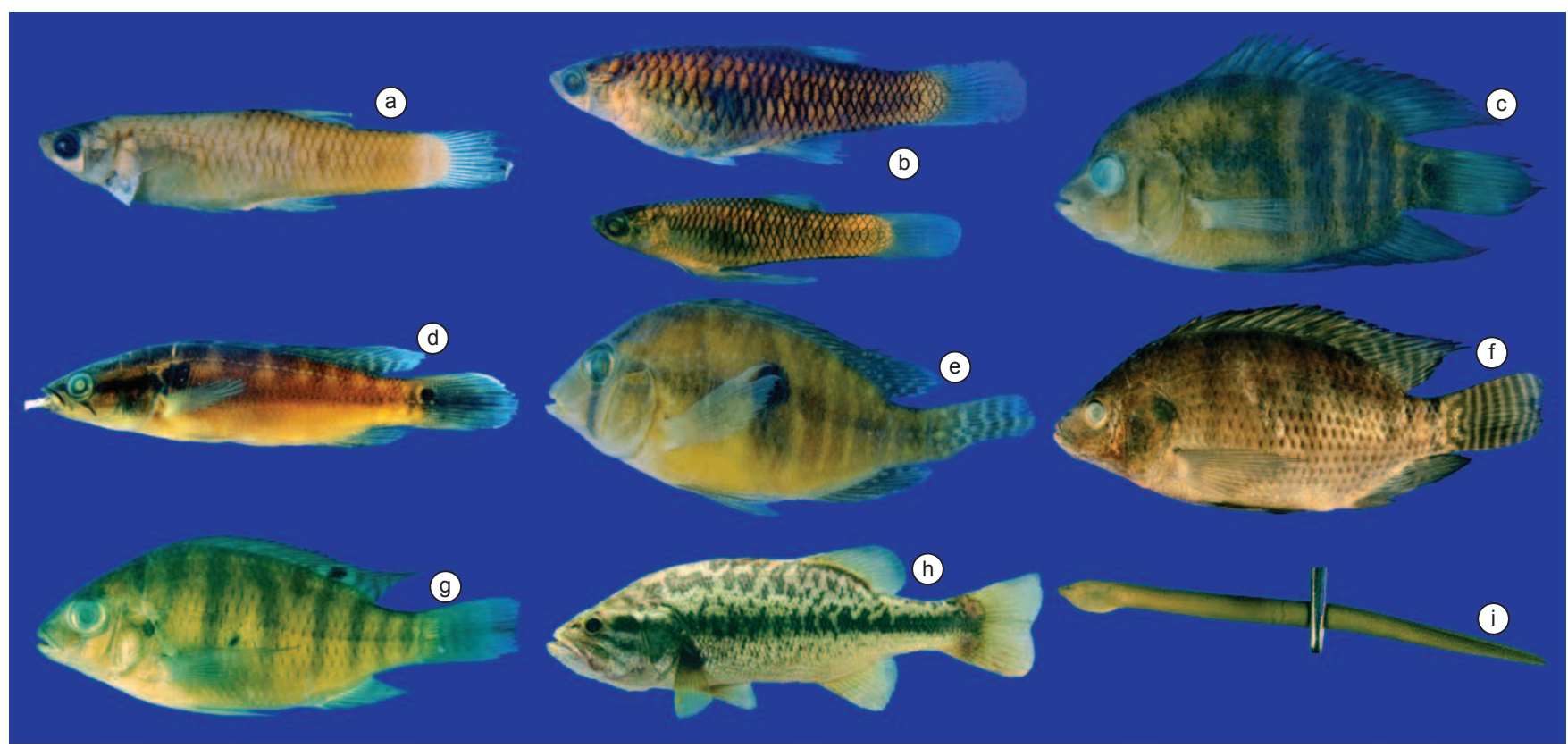

Figura 5. Espécies de peixes de cabeceiras do rio Tietê. Cyprinodontiformes: a) Phalloceros harpagos, MZUSP, 34,9 mm CP; b) Phalloceros reisi, DZSJRP 12829, fêmea 36,0 mm CP e macho 27,4 mm CP. Perciformes: c) Australoheros sp., exemplar não registrado, 86,9 mm CP; d) Crenicichla britskii, DZSJRP 12838, 61,5 mm CP; e) Geophagus brasiliensis, DZSJRP 12817, 71,6 mm CP; f) Oreochromis niloticus, DZSJRP 12837, 179,0 mm CP; g) Tilapia rendalli, DZSJRP 12815, 59,5 mm CP; h) Micropterus salmoides, exemplar não preservado; Synbranchiformes: i) Synbranchus cf. marmoratus, MZUSP 90370, 112,5 mm CP. Figure 5. Fish species of the headwater of rio Tietê. Cyprinodontiformes: a) Phalloceros harpagos, MZUSP, 34,9 mm CP; b) Phalloceros reisi, DZSJRP 12829, fêmea 36,0 mm CP e macho 27,4 mm CP. Perciformes: c) Australoheros sp., exemplar não registrado, 86,9 mm CP; d) Crenicichla britskii, DZSJRP 12838, $61,5 \mathrm{~mm}$ CP; e) Geophagus brasiliensis, DZSJRP 12817, 71,6 mm CP; f) Oreochromis niloticus, DZSJRP 12837, 179,0 mm CP; g) Tilapia rendalli, DZSJRP 12815, 59,5 mm CP; h) Micropterus salmoides, exemplar não preservado; Synbranchiformes: i) Synbranchus cf. marmoratus, MZUSP 90370, 112,5 mm CP.

\section{Agradecimentos}

Agradecemos ao DAEE (Departamento de Águas e Energia Elétrica) e a SABESP pelo apoio logístico durante as coletas no rio Biritiba e rio Claro, à FAEP (Fundação de Apoio ao Ensino e Pesquisa) e à UMC (Universidade de Mogi das Cruzes) pelo apoio institucional as atividades de pesquisas (APM e AWSH), a Marcos Daniel R. de Faria, Gustavo Zagolin, Milton Nunes de Santana, Denésio Leite de Almeida, Paulo Kazuo Nisidozi e aos pescadores da colônia de Taiaçupeba pelo auxílio na coletada de exemplares. Somos gratos a Dra. Carla Simone Pavanelli (Parodontidae), Dr. Flávio César T. de Lima (diversos táxons), Dr. Marcelo R. Britto (Callichthyidae) e ao Dr. Osvaldo T. Oyakawa (Erythrinidae) pelo auxílo na identificação de espécimes examinados, ao Museu de Zoologia da USP pela permissão de exame de material e a realização de imagens dos exemplares da coleção, e ao Dr. Naércio Aquino de Menezes (MZUSP) pela leitura e revisão do texto final. Agradecemos ao CNPq pelas bolsas de pesquisa de APM, AWSH, e FL; ao CNPq e à FAPESP pelo auxílio para estudo dos peixes do Alto Paraná (FL). O primeiro autor agradece ao IBAMA pela licença de coleta na região de cabeceiras do rio Tietê (número: 22146-1).

\section{Referências Bibliográficas}

AGOSTINHO, A.A. \& JÚLIO JUNIOR, H.F. 1999. Peixes da Bacia do Alto Rio Paraná. In Estudos Ecológicos de Comunidades de Peixes Tropicais (R.H. Lowe-Mcconnel, ed., A.E.A.M. Vazzoler, A.A. Agostinho \& P.T.M. Cunnhingham, trads.). São Paulo, EdUSP, p.374-400.

ALMEIDA, F.F.M. \& CARNEIRO, C.D.R. 1998. Origem e evolução da Serra do Mar. Rev. Bras. Geocienc. 28:135-150.
ALMEIDA, F.F.M., HASUI, Y., PONÇANO, W.L., DANTAS, A.S.L., CARNEIRO, C.D.R., MELO, M.S. \& BISTRICHI, C.A. 1981. Mapa Geológico do Estado de São Paulo. Instituto de Pesquisas Tecnológicas, São Paulo. Scale 1:500 000. IPT Monograph n. 6.

BARRELLA, W. \& PETRERE, M. 2003. Fish community alterations due to pollution and damming in Tietê and Paranapanema rivers (Brazil). River Res. Appl. 19:59-76. http://dx.doi.org/10.1002/rra.697

BÖHLKE, J.E., WEITZMAN, S.H. E MENEZES, N.A. 1978. Estado atual da sistemática dos peixes de água doce da América do Sul. Acta Amazonica 8(4):657-677.

BRITSKI, H.A. \& LANGEANI, F. 1988. Pimelodus paranaensis, sp. n., um novo Pimelodidae (Pisces, Siluriformes) do Alto Paraná, Brasil. Rev. Bras. Zool. 5(3):409-417. http://dx.doi.org/10.1590/S010181751988000300006

BUCKUP, P.A., MENEZES, N.A. \& GHAZZI, M.S. (Eds). 2007. Catálogo das espécies de peixes de água doce do Brasil. Rio de Janeiro, Museu Nacional, 195p.

CASTRO, R.M.C. 1999. Evolução da ictiofauna de riachos sul-americanos: padrões gerais e possíveis processos causais. In Ecologia de Peixes de Riachos: Estado Atual e Perspectivas (E.P. Caramaschi, R. Mazzoni, C.R.S.F. Bizerril \& P.R. Peres-Neto, eds.). PPGE-UFRJ, Rio de Janeiro, v. 6, p.139-155. Oecologia Brasiliensis.

CASTRO, R.M.C., CASATTI, L., SANTOS, H.F., FERREIRA, K.M., RIBEIRO, A.C., BENINE, R.C., PELIÇÃO, G.Z., MELO, A.L.A., STOPIGLIA, R., ABREU, T.X., BOCKMANN, F.A., CARVALHO, M., GIBRAN, F.Z. \& LIMA, F.C.T. 2003. Estrutura e composição da ictiofauna de riachos do Rio Paranapanema, sudeste e sul do Brasil. Biota Neotrop. 3(1): http://www.biotaneotropica.org.br/v3n1/pt/ abstract?article+BN01703012003. 
CASTRO, R.M.C., CASATTI, L., SANTOS, H.F., MELO, A.L.A., MARTINS L.S.F., FERREIRA, K.M., GIBRAN, F.Z., BENINE, R.C., CARVALHO, M., RIBEIRO, A.C., ABREU, T.X., BOCKMANN, F.A., PELIÇÃO, G.Z., STOPIGLIA, R., \& LANGEANI, F. 2004. Estrutura e Composição da ictiofauna de riachos da bacia do rio Grande no estado de São Paulo, sudeste do Brasil. Biota Neotrop. 4(1): http://www.biotaneotropica.org. br/v4n1/pt/abstract?article+BN01704012004.

CASTRO, R.M.C. \& MENEZES, N.A. 1998. Estudo diagnóstico da diversidade de peixes do Estado de São Paulo. In Biodiversidade do Estado de São Paulo, Brasil: síntese do conhecimento ao final do século XX (R.M.C. Castro, ed., C.A. Joly \& C.E.M. Bicudo, orgs.). WinnerGraphFAPESP, São Paulo, v. 6 - Vertebrados, p.1-13.

COMPANHIA DE TECNOLOGIA DE SANEAMENTO AMBIENTAL CETESB. 2009. Relatório de qualidade das águas interiores do estado de São Paulo 2008. Cetesb, São Paulo, 528p. Série Relatórios / CETESB. Disponível em: www.cetesb.sp.gov.br/Agua/rios/publicacoes.asp.

CETRA, M. \& PETRERE JUNIOR, M. 2007. Associations between fish assemblage and riparian vegetation in the Corumbataí River Basin (SP). Braz. J. Biol. 67(2):191-195. http://dx.doi.org/10.1590/S151969842007000200002

COX, C.B. \& MOORE, P.D. 2000. Biogeography, an ecological and evolutionary approach. Blackwell Science, London.

EIGENMANN, C.H. 1911. New characins in the collection of the Carnegie Museum. Ann. Carnegie Mus. 8(3):164-181.

EIGENMANN, C.H. 1917. Pimelodella and Typhlobagrus. Mem. Carnegie Mus. 7(4):229-258.

EIGENMANN, C.H. \& NORRIS, A.A. 1900. Sobre alguns éixes de São Paulo, Brasil. Rev. Mus. Paul. 4:349-362.

ELLIS, M.D. 1911. On the species of Hasemania, Hyphessobrycon and Hemigrammus collected by J.D. Haseman for the Carnegie Musem. Ann. Carnegie Mus. 8(2):148-163.

ESTEVES, K.E., LÔBO, A.V.P. \& FARIA, M.D.R. 2008. Trophic structure of a fish community along environmental gradients of a subtropical river (Paraitinga River, Upper Tietê River basin, Brazil). Hydrobiologia 598:373-387. http://dx.doi.org/10.1007/s10750-007-9172-4

FERRAZ, D. 2000. Tietê: imagens que um Brasil não vê. D. Ferraz, Suzano, $90 \mathrm{p}$.

FROESE, R. \& PAULY, D., eds. 2010. FishBase. Disponível em: www. fishbase.org (último acesso em 05/2010).

GALVES, W., SHIBATTA, O.A. \& JEREP, F.C. 2009. Estudos sobre diversidade de peixes da bacia do alto rio Paraná: uma revisão histórica. Semina. 30(2):141-154.

GARUTTI, V. \& BRITSKI, H.A. 2000. Descrição de uma espécie nova de Astyanax (Teleostei: Characidae) da bacia do Alto rio Paraná e considerações sobre as demais espécies do gênero na bacia. Comun. Mus. Ciênc. Tecnol. PUCRS, Sér. Zool. Porto Alegre. 65-88.

GÉRY, J. 1966. A review of certain Tetragonopterinae (Characoidei), with the description of two new genera. Ichthyologica. The Aquarium J. 37:211-236.

GIAMAS, M.T.D., CAMPOS, E.C., DA CÂMARA, J.J.C., VERMULM, H.J.R. \& BARBIERI, G. 2004. A ictiofauna da represa de Ponte Nova, Salesópolis (São Paulo) - bacia do Alto Tietê. Bol. Inst. Pesca 30:25-34.

HASEMAN, J.D. \& EIGENMANN, C.H. 1911. A brief report upon the expedition of the Carnegie Musem to central South America. Together with a list of localities at wich Mr. Haseman collected. Ann. Carnegie Mus. 7:315-328.

LANGEANI, F. 1989. Ictiofauna do Alto Curso do Rio Tietê (SP): Taxonomia. Dissertação de mestrado, Universidade Estadual Paulista, São José do Rio Preto, 231p.

LANGEANI, F., BUCKUP, P.A., MALABARBA, L.R., PY-DANIEL, L.H.R., LUCENA, C.A.S., ROSA, R.S., ZUANON, J.A.S., LUCENA, Z.M.S., DE BRITTO, M.R., OYAKAWA, O.T. \& GOMES-FILHO, G. 2009. Peixes de Água Doce. In Estado da arte e perspectivas para a zoologia no Brasil (Rocha, R.M. \& W.A.P. Boeger, orgs.). Curitiba, Ed. UFPR, p. 211-230.
LANGEANI, F., CASTRO, R.M.C., OYAKAWA, O.T., SHIBATTA, O.A., PAVANELLI, C.S. \& CASATTI, L. 2007. Diversidade da ictiofauna do Alto rio Paraná: composição atual e perspectivas futuras. Biota Neotrop. 7(3): http://www.biotaneotropica.org.br/v7n3/pt/ abstract?article+bn03407032007

LEPRIEUR, F., OLIVIER BEAUCHARD, O., BLANCHET, S., OBERDORFF, T. \& BROSSE, S. 2008. Fish Invasions in the World's River Systems: When Natural Processes Are Blurred by Human Activities. PLoS Biol. 6(2):e28. PMid:18254661. PMCid:2225436 http://dx.doi.org/10.1371/ journal.pbio.0060028

LOWE-McCONNELL, R.W. 1999. Estudos ecológicos de comunidades de peixes tropicais. EdUSP, São Paulo, 453p.

MACHADO, A.B.M., DRUMMOND, G.M. \& PAGLIA, A.P., eds. 2008. Livro vermelho da fauna brasileira ameaçada de extinção. MMA, Brasília, 1420p. http://www.mma.gov.br/port/sbf/fauna/index.html

MALABARBA, L.R. \& REIS, R.E. 1987. Manual de técnicas para a preparação de coleções zoológicas. Soc. Brasil. Zool. 36:1-14.

MAZZONI, R., FENERICH-VERANI, N. \& CARAMASCHI, E.P. 2000. Electrofishing as a sampling technique for coastal stream fish population and communities in the Southeast of Brazil. Rev. Brasil. Biol. 60:205-216.

MATTOX, G.M.T. \& IGLESIAS, J.M.P. 2010. Ichthyofauna of Rio Jurubatuba, Santos, São Paulo: a high diversity refuge in impacted lands. Biota Neotrop. 10(1): http://www.biotaneotropica.org.br/v10n1/ pt/abstract?article+bn01710012010

MORAES, J.F.L., DE CARVALHO, J.P. \& CARLSTROM FILHO, A.A. 2004. Caracterização e evolução do uso da terra na sub-bacia Tietê-Cabeceiras. Annu. Rep. Eur. Community. 2(1):87-97.

MORTATTI, J., CHRISTOPHE HISSLER, C. \& PROBST, J.L. 2010. Distribuição de metais pesados nos sedimentos de fundo ao longo da bacia do rio Tietê. Rev. Inst. Geocienc. 10(2):3-11.

NICHOLS, J.T. 1919. Um novo gênero de cascudo da família Loricariidae. Rev. Mus. Paul. 11:10.

NOGUEIRA, C., BUCKUP, P.A., MENEZES, N.A., OYAKAWA, O.T., KASECKER, T.P., RAMOS NETO, M.B. \& SILVA, J.M.C. 2010. Restricted-Range fishes and the conservation of Brazilian freshwaters. PLoS ONE 5(6):e11390. PMid:20613986. PMCid:2894945. http://dx.doi. org/10.1371/journal.pone.0011390

OLIVEIRA, J.C. \& BRITSKI, H.A. 2000. Redescrição de Taunaya bifasciata (Eigenmann \& Norris, 1900), comb. nova, um bagre enigmático do Estado de São Paulo (Siluriformes, Pimelodidae, Heptapterinae). Pap. Av. Zool. 41:119-133.

OYAKAWA, O.T., MENEZES, N.A., SHIBATTA, O.A., LIMA, F.C.T., LANGEANI, F., PAVANELLI, C.S., NIELSEN, D.T.B. \& HILSDORF, A.W.S. 2009. Peixes de água doce. In Fauna ameaçada de extinção no estado de São Paulo: vertebrados. (M.P. Bressan, M.C.M. Kierulff \& A.M. Sugieda, eds). Imprensa Oficial, São Paulo, p.349-424.

PONÇANO, W.L., CARNEIRO, C.D.R., BISTRICHI, C.A., DE ALMEIDA, F.F.M. \& PRANDINI, F.L. 1981. Mapa Geomorfológico do Estado de São Paulo. São Paulo: Instituto de Pesquisas Tecnológicas. 94p. (Publicação n. 1183).

REIS, R.E., KULLANDER, S.O. \& FERRARIS-JUNIOR, C.J., orgs. 2003. Check list of the freshwater fishes of South and Central America. EdPUCRS, Porto Alegre.

RIBEIRO, A.C. 2006. Tectonic history and the biogeography of the freshwater fishes from the coastal drainages of eastern Brazil: an example of faunal evolution associated with a divergent continental margin. Neotrop. Ichthyol. 4(2):225-246. http://dx.doi.org/10.1590/S167962252006000200009

RIBEIRO, A.C., LIMA, F.C.T., RICCOMINI, C. \& MENEZES, N.A. 2006. Fishes of the Atlantic Rainforest of Boracéia: testimonies of the Quaternary fault reactivation within a Neoproterozoic tectonic province in Southeastern Brazil. Ichthyol. Explor. Freshw. 17(2):157-164.

ROCHA, A.A. 1991. Do Lendário Anhembi ao Poluído Tietê. EdUSP, São Paulo, 75p. 
ROSA, R.S. \& LIMA, F.C.T. 2008. Os peixes brasileiros ameaçados de extinção. In Livro vermelho da fauna brasileira ameaçada de extinção (A.B.M. Machado, G.M. Drummond \& A.P. Paglia, eds.). MMA, Brasília, p. 9-285. http://www.mma.gov.br/port/sbf/fauna/index.html

SÃO PAULO (Estado). Departamento de Águas e Energia Elétrica - DAEE. 2010. Sistema Produtor Alto Tietê. Disponível em: http://www.daee. sp.gov.br

SCHRÖEDER-ARAÚJO, L.T. 1980. Alimentação dos peixes da represa de Ponte Nova, Alto Tietê. Tese de doutorado, Universidade de São Paulo, São Paulo, 88p.

SERRA, J.P., CARVALHO, F.R. \& LANGEANI, F. 2007. Ichthyofauna of the rio Itatinga in the Parque das Neblinas, Bertioga, São Paulo: composition and biogeography. Biota Neotrop. 7(1): http://www.biotaneotropica.org. br/v7n1/pt/abstract?article+bn01707012007.

SILVA, F.S.D., MANNA-DE-DEUS, J.R. \& HILSDORF, A.W.S. 2006. The upper reached ichthyofauna of the Tietê River, São Paulo, Brazil: aspects of their diversity and conservation. Biodivers. Conserv. 15(11):3569-3577. http://dx.doi.org/10.1007/s10531-004-1460-y

SILVA, C.C.F., DA MATTA, S.L.S.F., HILSDORF, A.W.S., LANGEANI, F. \& MARCENIUK, A.P. 2010. Color pattern variation in Trichomycterus iheringi (Eigenmann, 1917) (Siluriformes: Trichomycteridae) from rio Itatinga and rio Claro, São Paulo, Brazil. Neotrop. Ichthyol. 8(1):49-56.

SOLIA, M., FARIA, O.M. \& ARAÚJO, R. 2007. Mananciais da região metropolitana de São Paulo. Sabesp, São Paulo.
SOUZA FILHO, E.E. \& STEVAUX, J.C. 1997. Geologia e geomorfologia do complexo Rio Baía, Curutuba, Ivinheima. In A planície de inundação do Alto Rio Paraná: aspectos físicos, biológicos e sócio-econômicos (A.E.A.M. Vazzoler, A.A. Agostinho \& N.S. Hahn., eds.). EdUEM, Maringá, p.3-46.

TAGNIN, R.A. \& MAGALHÃES, E.W. 2001. O tratamento da expansão urbana na Proteção aos Mananciais - o caso da Região Metropolitana de São Paulo. Boletim Técnico da Escola Politécnica da USP. Disponível em: http://publicacoes.pcc.usp.br/PDF/BTPCC278.pdf

TRAVASSOS, H. 1947. Contribuição ao estudo da família Characidae Gill, 1893. V - redescrição do genótipo de Characidium Reinhardt, 1866, com uma análise da 45 literatura e descrição de Characidium lagosantensis n. sp. (Actinopterygii - Ostariophysi). Summa Bras. Biol. 1(14):1-59.

VARI, R.P. \& CASTRO, R.M.C. 2007. New Species of Astyanax (Ostariophysi: Characiformes: Characidae) from the Upper Rio Paraná System, Brazil. Copeia. (1):150-162. http://dx.doi.org/10.1643/00458511(2007)7[150:NSOAOC $] 2.0 . C O ; 2$

von IHERING, R. 1905. Descriptions of four new Loricariidae of the genus Plecostomus from Brazil. Ann. Mag. Nat. Hist. 7(15):558-581.

von IHERING, R. 1907. Diversas especies novas de peixes nemathognathas do Brazil. Notas preliminares. Rev. Mus. Paul. 1(1):13-39.

von IHERING, R. 1942. Piscicultura. Os peixes no seu ambiente natural. O que ocorre nas águas do Tietê. Caça e Pesca 14:42-44.

WELCOMME, R.L. 1988. International introductions of inland aquatic species. FAO Fisheries Technical Papers 294:1-318.

Recebido em 11/10/2010

Versão reformulada recebida em 01/05/2011

Publicado em 04/07/2011 


\section{Chave de identificação}

\section{Espécies das cabeceiras do rio Tietê}

1. Corpo serpentiforme; uma única abertura branquial pequena na porção ventro-posterior da cabeça; nadadeiras dorsal, anal, peitoral e pélvica ausentes Synbranchus cf. marmoratus (Synbranchiformes)

1'. Corpo não serpentiforme; aberturas branquiais na porção lateral cabeça; nadadeiras dorsal, anal, peitoral e pélvica normalmente presentes ... 2

2. Quilha ventral anterior formada por escamas modificadas em espinhos conspícuos Platanichthys platana (Clupeiformes)

2'. Quilha ventral anterior (formada por escamas modificadas em espinhos) ausente.

3. Nadadeiras dorsal, pélvica e caudal ausentes; nadadeira anal com mais de 100 raios...4 (Gymnotiformes)

3'. Nadadeiras dorsal, pélvica e caudal presentes; nadadeira anal com menos de 60 raios

4. Mandíbula mais curta que a maxila superior; duas listras longitudinais presentes no flanco......Eigenmannia cf. virescens (Sternopygidae) 4'. Mandíbula prognata, listras longitudinais ausentes nos flancos .5 (Gymmotidae)

5. Corpo relativamente cilíndrico, com linhas claras e estreitas formando um padrão vermiculado sobre fundo castanho-escuro.....

Gymnotus pantherinus

5'.Corpo relativamente comprimido, com faixas castanho claras estreitas, intercaladas por faixas escuras e mais largas..... Gymnotus sylvius

6. Corpo nu ou revestido por placas ósseas; barbilhões maxilares ou mentonianos presentes 7 (Siluriformes)

6'. Corpo revestido por escamas; barbilhões maxilares ou mentais ausentes.

7. Corpo totalmente nu, sem placas ósseas ......

7'. Corpo parcial ou totalmente coberto por placas ósseas

8. Região opercular com odontoides bem desenvolvidos; barbilhão nasal presente; nadadeira adiposa ausente. 9 (Trichomycteridae)

8'. Região opercular sem odontoides; barbilhão nasal ausente; nadadeira adiposa presente 10 (Heptapteridae)

9. Corpo com manchas arredondadas de número e tamanho variável

Trichomycterus iheringi

9'. Corpo com três faixas longitudinais castanho-escuras, ao longo da região médio-lateral (a mais conspícua), abaixo da base da nadadeira dorsal e pouco acima da base da nadadeira pélvica. Trichomycterus paolence

10. Olho sem margem orbital livre, totalmente coberto por pele.

10'. Olho com margem orbital livre.

11. Barbilhão maxilar ultrapassa a base da nadadeira peitoral; corpo uniformemente castanho-escuro dorsalmente e castanho-claro ventralmente; uma banda castanho-escura conspícua no pedúnculo caudal; nadadeira caudal furcada

Cetopsorhamdia iheringi

11'. Barbilhão maxilar não ultrapassa a borda lateral da cabeça; faixa médio-lateral larga, mais conspícua anteriormente; faixa para-dorsal mais estreita, da porção posterior da cabeça à vertical que passa pelo início da base da nadadeira adiposa; estria transversal larga após a cabeça; nadadeira caudal truncada

Taunaya bifasciata

12. Primeiro raio das nadadeiras dorsal e peitoral transformados em acúleo pungente

Pimelodella meeki

12'. Primeiro raio das nadadeiras dorsal e peitoral bastante ossificados ou relativamente moles, nunca formando acúleo pungente..... .13

13. Barbilhão maxilar curto, ultrapassando a vertical que passa pela origem da nadadeira dorsal; nadadeira adiposa relativamente curta, algo maior que a base da nadadeira anal

Imparfinis piperatus

13'. Barbilhão maxilar longo, ultrapassando a vertical que passa pela origem da nadadeira adiposa; nadadeira adiposa longa, cerca de três vezes mais longa que a base da nadadeira anal

Rhamdia cf. quelen

14. Quatro a cinco séries longitudinais e laterais de placas ósseas no corpo; boca inferior, em forma de ventosa

15 (Loricariidae)

14'. Duas séries de placas longitudinais e laterais de placas ósseas no corpo; boca subterminal, não em forma de ventosa

20 (Callichthyidae)

15. Mecanismo de trava da nadadeira peitoral ausente, representado por uma placa pequena, anterior ao primeiro raio da nadadeira dorsal...

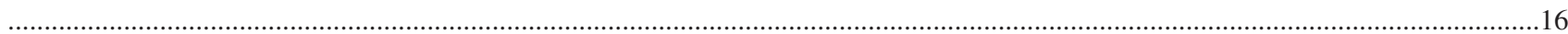

15'. Mecanismo de trava da nadadeira peitoral presente

16. Nadadeira adiposa presente; duas a três séries de papilas após o ramo de dentes do dentário, maiores e mais desenvolvidas do que aquelas do restante do lábio inferior. .Neoplecostomus paranensis 
16'. Nadadeira adiposa ausente; papilas após o ramo de dentes do dentário de mesmo tamanho que aquelas do restante do lábio inferior ......

17. Cintura escapular totalmente recoberta por pele espessa; ventre nu, sem placas Pareiorhina sp.n.

17'. Cintura escapular exposta total ou parcialmente; ventre revestido por placas

18. Cintura escapular exposta apenas lateralmente; pedúnculo caudal de secção retangular; fenda peitoral ausente.

Pseudotocinclus tietensis

18'. Cintura escapular totalmente exposta; pedúnculo caudal de secção ovalada; fenda peitoral grande e conspícua, abaixo do processo cleitral Hisonotus depressicauda

19. Máculas escuras e pequenas Hypostomus ancistroides

19'. Máculas claras e relativamente grandes.

Hypostomus variipictus

20. Barbilhões maxilares longos, ultrapassando a base do acúleo peitoral; espinho dorsal curto, menos da metade do comprimento do primeiro raio mole

Hoplosternum cf. littorale

20'. Barbilhões maxilares curtos, nunca alcançando a base do acúleo peitoral; espinho dorsal longo, mais da metade do comprimento do primeiro raio mole .21

21. Focinho relativamente longo, menos de duas vezes no comprimento da cabeça; corpo amarelado a castanho-claro, com manchas difusas castanho-escuras; nadadeira caudal com faixas transversais castanho-escuras Scleromystax barbatus

21'. Focinho curto, duas vezes ou mais no comprimento da cabeça; colorido distinto do acima .22

22. Faixa negra conspícua e estreita, na altura da junção das placas laterais Corydoras nattereri

22'. Porção látero-dorsal do corpo, equivalente à série superior de placas latarais, castanho-escura Corydoras aeneus

23. Pré-maxilar protráctil; nadadeira adiposa ausente .24

23'. Pré-maxilar não protráctil; nadadeira adiposa normalmente presente (exceto Erythrinidae)

31 (Characiformes)

24. Linha lateral corpórea ausente; escamas ciclóides; nadadeiras dorsal, anal e pélvica apenas com raios moles ... 25 (Cyprinodontiformes)

24'. Linha lateral corpórea presente; escamas ctenóides; nadadeiras dorsal, anal e pélvica com os primeiros raios transformados em espinhos .26 (Perciformes)

25. Papila urogenital da fêmea na linha média do corpo, entre o ânus e a base do primeiro raio da nadadeira anal ... Phalloceros reisi 25' Papila urogenital da fêmea lateral, ânus em contacto com a base do primeiro raio da nadadeira anal Phalloceros harpagos

26. Linha lateral corpórea única, não dividida em dois ramos Micropterus salmoides

26'. Linha lateral corpórea dividida em dois ramos, um anterior, mais dorsal, e outro posterior, na linha médio-lateral do corpo

27. Margem posterior do pré-opérculo serrilhada; corpo baixo, sua maior altura contida 3,2 a 5 vezes no comprimento padrão Crenicichla britskii

27'. Margem posterior do pré-opérculo lisa; corpo alto, sua maior altura contida menos de 3 vezes no comprimento padrão .28

28. Nadadeira anal com 5 ou mais espinhos Australoheros sp.

28'. Nadadeira anal com 3 espinhos

29. Ramo superior do primeiro arco branquial com lóbulo desenvolvido; mácula médio-lateral grande escura e ovalada; faixa escura cruzando a órbita dorso-ventralmente Geophagus brasiliensis

29’. Ramo superior do primeiro arco branquial sem lóbulo; mácula médio-lateral ausente; faixa escura cruzando a órbita ausente 30

30. Ramo inferior do primeiro arco branquial com mais de 20 rastros longos e delgados; nadadeira caudal com várias faixas transversais escuras e claras

Oreochromis niloticus

30'. Ramo inferior do primeiro arco branquial com menos de 15 rastros curtos e espessos; nadadeira caudal sem faixas transversais.

Tilapia rendalli

31. Maxilas superior e inferior totalmente desprovidas de dentes. 32 (Curimatidae)

31'. Maxilas superior ou inferior parcial ou completamente denteadas

32. Corpo uniformemente castanho, com o dorso pouco mais escuro que o ventre; uma faixa longitudinal castanho-escura, sobre a linha lateral, desde a vertical que passa pela origem da nadadeira dorsal até os raios caudais medianos, sendo mais conspícua e alta no pedúnculo caudal... 
32'. Corpo com uma série de listras longitudinais laterais, desde o dorso até a altura da nadadeira peitoral, entre as séries de escamas; faixa longitudinal mais alta, sobre a linha lateral, presente como acima, porém menos conspícua.....

Cyphocharax sp.

33. Dentário sem dentes; borda anterior da mandíbula reta. Apareiodon piracicabae (Parodontidae)

33’.Dentário com dentes bem desenvolvidos; borda anterior da mandíbula arredondada......

34. Prémaxilar com duas séries de dentes

34'. Pré-maxilar com uma única série de dentes

35. Dentário com duas séries de dentes, a posterior com dentes pequenos envolvidos por tecido cutâneo

Salminus hilarii

35'. Dentário com uma única série de dentes

36 (Characidae incertae sedis)

36. Boca superior, mandíbula prognata; machos com escamas grandes e modificadas cobrindo a base dos raios caudais medianos superiores ou inferiores; região supra-orbital com uma depressão de tamanho variável e poros da linha lateral cefálica supra-orbital

36'. Boca terminal; base dos raios caudais medianos não coberta por escamas, ou coberta por escamas de mesmo tamanho que as do restante do corpo; região supra-orbital sem depressão, apenas com poros da linha lateral cefálica supra-orbital

37. Porção ventral entre a cabeça e nadadeira pélvica arredondada; nadadeira peitoral curta, ultrapassando ligeiramente a vertical que passa pela origem da pélvica......

Glandulocauda melanopleura

37'. Porção ventral entre a cabeça e a nadadeira pélvica quilhada; nadadeira peitoral longa, ultrapassando ou quase a vertical que passa pela extremidade posterior da pélvica. Pseudocorynopoma heterandria

38. Linha lateral incompleta ..... .39

38'. Linha lateral completa

39. Listras negras longitudinais estreitas ao longo do flanco; nadadeira adiposa com base castanho-escura e emarginada de castanho-escuro Hollandichthys multifasciatus

39'. Padrão de colorido bastante variável, mas nunca como acima; nadadeira adiposa nunca emarginada por uma faixa estreita castanho-escura.

40. Duas máculas umerais conspícuas

40’. Uma mácula umeral; eventualmente uma segunda, inconspícua

41. Uma série de máculas estreitas, médio laterais, em forma de "v" deitado para trás; nadadeira anal com mais de 28 raios totais

Hyphessobrycon bifasciatus

41'. Máculas médio laterais em forma de "v" ausentes; nadadeira anal com 25 ou menos raios totais

Hyphessobrycon flammeus

42. Nadadeira anal longa, com 28 ou mais raios totais; menos 8 escamas perfuradas na linha lateral .....

Hyphessobrycon eques

42'. Nadadeira anal curta, com 27 ou menos raios totais; mais de 8 escamas perfuradas na linha lateral.

43. Pedúnculo caudal baixo, 10 a $13 \%$ do $\mathrm{CP}$; nadadeira anal com iii a iv +21 a 24 raios

Hyphessobrycon cf. anisitsi

43'. Pedúnculo caudal alto, $14 \%$ do CP; nadadeira anal com iv +16 raios

Hyphessobrycon duragenys

44. Mácula umeral horizontalmente ovalada; maxilar sem dentes; nadadeira caudal amarelada.....

Astyanax cf. altiparanae

44'. Mácula umeral verticalmente alongada; maxilar com dentes; nadadeira caudal amarelada ou avermelhada.

45. Linha transversal com 5+1+4 séries longitudinais de escamas; nadadeira anal com iii a iv + 15 a 18 raios; nadadeira caudal amarelada; corpo não prateado. Astyanax paranae

45'. Linha transversal com 6-7 + $1+5-6$; nadadeira caudal avermelhada; corpo prateado .46

46 Nadadeira anal com iii a iv +26 a 31 raios; linha lateral com 37 a 41 escamas perfuradas

Astyanax cf. fasciatus

46' Nadadeira anal com iii a iv + 19 a 23 raios; linha lateral com 34 a 37 escamas perfuradas.

Astyanax sp. n.

47. Dentes no maxilar ausentes

.48 (Crenuchidae)

47'. Dentes no maxilar presentes

48. Istmo com escamas; 7 a 8 barras transversais, laterais e escuras, bastante conspícuas da largura da órbita

Characidium cf. zebra

48'. Istmo sem escamas; faixa médio-lateral, longitudinal e conspícua, na altura do olho, relativamente larga; outras 3, mais estreitas e dorsais.

49. Faixa médio-lateral mais estreita do que o olho; 8 a 10 barras transversais pouco conspícuas.

Characidium oiticicai

49'. Faixa médio-lateral mais larga do que o olho; barras transversais ausentes

Characidium sp.n. 
50. Nadadeira adiposa ausente; corpo roliço, e alongado, quase cilíndrico 51 (Erythrinidae)

50'. Nadadeira adiposa presente; corpo moderada a marcadamente comprimido lateralmente .52

51. Margens mediais dos dentários convergindo abruptamente em direção à sínfise mandibular, formando um "v" em vista ventral; língua com pequenos dentes; linha lateral com 38 a 43 escamas perfuradas Hoplias cf. malabaricus

51'. Margens mediais dos dentários quase paralelas; lingua lisa, sem dentes; linha lateral com 42 a 46 escamas perfuradas...... Hoplias intermedius

52. Pré-maxilar e dentário com dentes cônicos e caninos; palato com dentes; pseudotímpano ausente. Oligosarcus paranensis

52'. Pré-maxilar e dentário com dentes cônicos ou cuspidados; palato sem dentes; pseudotímpano presente 53 (Cheirodontinae)

53. Nadadeira adiposa ausente; dentes cônicos ou ligeiramente tricúspides Spintherobolus papilliferus

53'. Nadadeira adiposa presente; dentes multicuspidados ..Serrapinnus notomelas 
Anexo I. Lista do material examinado e nomenclatura adotada em estudos recentes.

Annex I. Material examined and nomenclature adopted in previous studies.

Apareiodon piracicabae [como Apareiodon affinis (Steindachner 1879) em Giamas et al. (2004); Figura 3a]: NUP 9542, 2 ex., reservatório de Taiçupeba, Mogi das Cruzes, 23 39' 08.7”' S e 46 10' 12.0”' O; NUP 6977, 1 ex., reservatório Jundiaí, Mogi das Cruzes, $23^{\circ} 37^{\prime} 37.9^{\prime \prime} \mathrm{S}$ e 460 12' 15.6" O; NUP 7028, 1 ex., cabeceiras do rio Tietê.

Astyanax cf. altiparanae [como Astyanax bimaculatus (Linnaeus 1758) em da Silva et al. (2006); Figura 31]: MZUSP 86922, 6 ex., rio Tietê, área da Mineradora VCN, Biritiba Mirim, 23 34' 04.5" S e 4600'38.4" O; DZSJRP 12720, 1 ex., reservatório de Taiaçupeba,

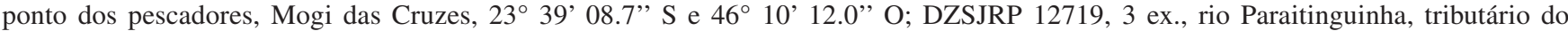

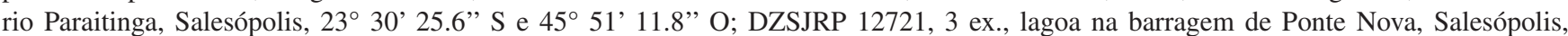
$23^{\circ} 35^{\prime} 55.4^{\prime \prime} \mathrm{S}$ e $45^{\circ} 58^{\prime} 02.1$ ' O.

Astyanax cf.fasciatus (Figura 3m): MZUSP 86923, 10 ex., rio Tietê, área da Mineradora VCN, Biritiba Mirim, 23 34'04.5” S e 46 00' 38.4”' O; DZSJRP 12834, 6 ex., reservatório de Ponte Nova, Salesópolis, 2335'06.6” S e 45 58’21.6” O.

Astyanax paranae [como Astyanax scabripinnis (Jenyns 1842) em Castro \& Arcifa (1987), Giamas et al. (2004), da Silva et al. (2006); como Astyanax scabripinnis paranae Eigenmann 1914 em Langeani (1989); Figura 3n]: MZUSP 36629, 115 ex., afluente do rio Claro, adutora da SABESP, Salesópolis, 23 32' 00" S e 45 51'00" O; MZUSP 28173, 4 ex., reservatório de Ponte Nova, Salesópolis,

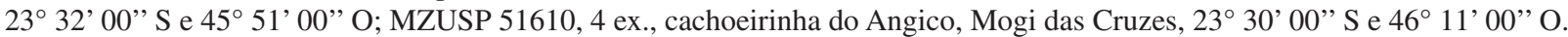

Astyanax sp. [como Astyanax eigenmanniorum em Langeani (1989), Giamas et al. (2004), da Silva et al. (2006); Figura 3o]: MZUSP 87581, 14 ex., afluente do rio Claro, na estrada para a estação elevatória do Guaratuba, Salesópolis, 23 39' 23' 'S e 45 54' 53"' O; MZUSP 26887, 3 ex., rio Tiete, km 18 da estrada Mogi-Salesópolis, Mogi das Cruzes, 23 30’ 00”' S e 46 12' 00”' O; MZUSP 28175 , 7 ex., reservatório

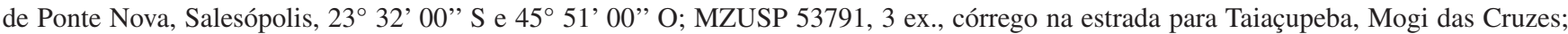
MZUSP 18517, 66 ex., represa de Salesópolis, Salesópolis, 2332’00” S e 45 51'00" O.

Australoheros sp.[como Cichlasoma facetum em Langeani (1989), da Silva et al. (2006); Figura 5c]: MZUSP 28169, 10 ex., reservatório de Ponte Nova, Salesópolis, $23^{\circ}$ 32' 00" S e 45 51' 00" O; MZUSP 59138, 1 ex., rio Paraitinga, cachoeira da Porteira, Salesópolis,

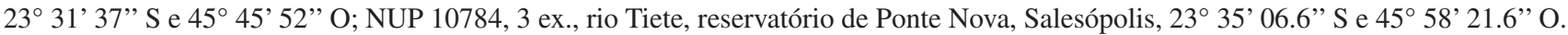

Cetopsorhamdia iheringi (Figura 4m): MZUSP 36632, 1 ex., afluente do rio Claro, adutora da SABESP, Salesópolis,

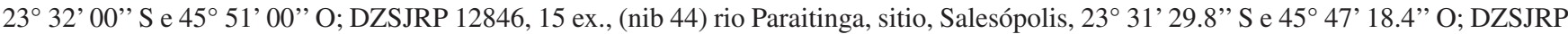

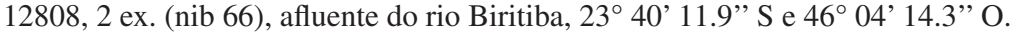

Characidium oiticicai (Figura 3e): DZSJRP 12842, 1 ex., rio Paraitinga, Salesópolis, 23 31' 29.8" S e 45 47' 18.4" O; MZUSP 36636, 10 ex., afluentes do rio Claro, adutora da SABESP, Salesópolis, $23^{\circ} 32^{\prime} 00^{\prime \prime} \mathrm{S}$ e $45^{\circ} 51^{\prime} 00^{\prime \prime} \mathrm{O}$.

Characidium sp. (Figura 3g): DZSJRP 11424, 2 ex., rio Paraitinga, Salesópolis, 23 31' 29.8" S e 45 47' $18.4^{\prime \prime} \mathrm{O}$.

Characidium cf. zebra (Figura 3f): DZSJRP 11423, 1 ex., rio Paraitinga, Salesópolis, 23 31' 29.8' S e 45 47' 18.4" O

Coptobrycon bilineatus (Figura 3p): ZUEC-PIS 4287, 4 ex., rio Tietê, Mogi das Cruzes, 23 52' 56" S e 46 $18^{\prime}$ '56" O.

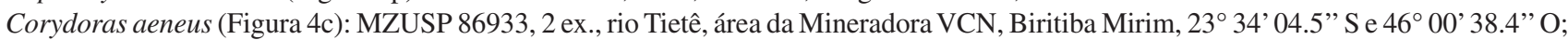
MZUSP 59126, 6 ex., córrego na estrada Biritiba-Mirim-Casa Grande, Biritiba Mirim, 23 34' 29" S e 46 $01^{\circ}$ ' $03^{\prime \prime}$ O.

Corydoras nattereri (Figura 4d): DZSJRP 12844, 3 ex., rio Paraitinga, Salesópolis, 23 31' 29.8” S e 45 47' 18.4” O; DZSJRP 12816, 1 ex., canal de acesso ao reservatorio Jundiaí, 23 38' 26.3" 'S e 46 08' 01.8” O; DZSJRP 12848, 2 ex., rio Tietê, na ponte Santa Catarina, Biritiba Mirim, $23^{\circ} 33^{\prime}$ 21.6" S 46 02' 26.8”' O; MZUSP 53792, 8 ex., córrego na estrada a 2 km do reservatório de Taiaçupeba, Mogi das Cruzes. Crenicichla britskii (Figura 5d): DZSJRP 12838, 1 ex., rio Biritiba, 23 40' 25.8' S e 46 04' 53.8”' O; DZSJRP 12835, 1 ex., reservatório de Taiaçupeba, Mogi das Cruzes, 23 39'08.7' S e 46 10'12.0” O.

Cyphocharax modestus (Figura 3c): MZUSP 86929, 1 ex., rio Tietê, área da Mineradora VCN, Biritiba Mirim, 23³4'04.5”'S e 4600'38.4” O; MZUSP 28159, 93 ex., reservatório Ponte Nova, Salesópolis, $23^{\circ} 32^{\prime} 00^{\prime \prime} \mathrm{S}$ e 4551'00” O.

Cyphocharax sp. (como Steindachnerina insculpta (Fernández-Yépez 1948) em Giamas et al. (2004); Figura 3d]: DZSJRP 12831, 1 ex.,

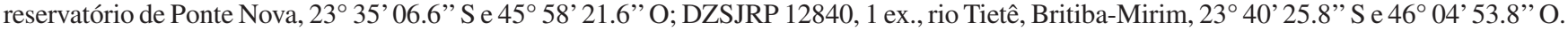

Eigenmannia cf. virescens (Figura 4t): MZUSP 28164, 20 ex., reservatório de Ponte Nova, Salesópolis, 23 32' 00”' S e 45 51' 00"' O; MZUSP 24822, 1 ex., reservatório de Salesópolis, 2332'00”' S e 4551'00” O.

Geophagus brasiliensis (Figura 5e): MZUSP 86936, 1 ex., rio Tietê, área da Mineradora VCN, Biritiba Mirim, 233 34'04.5”' Se , 46 00’38.4”' O;

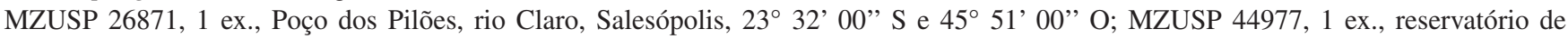

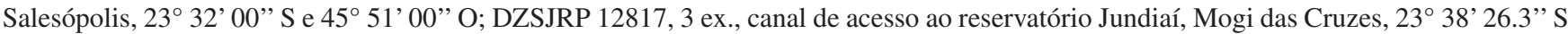

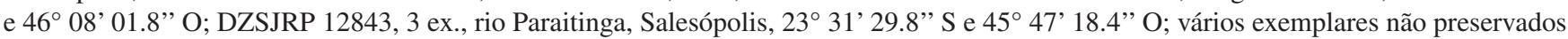
dos reservatórios de Ponte Nova e Taiçupeba.

Glandulocauda melanopleura [como Glandulocauda melanogenys Eigenmann 1911 em Langeani (1989), da Silva et al. (2006); Figura 3j]: MZUSP 87567, 23 ex., afluente do rio Guaratuba, na trilha do mirante, Salesópolis, $23^{\circ} 40^{\prime} 08^{\prime \prime} \mathrm{S}$ e 455 53' 55" O.

Gymnotus pantherinus (Figura 4s): MZUSP 59137, 1 ex., rio Paraitinga, acima da cidade Salesópolis, 233 31' 26" S e 45 48' 09" O;

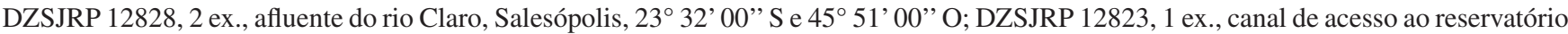
Jundiaí, Mogi das Cruzes, $23^{\circ} 38^{\prime} 26.3^{\prime \prime}$ S e $46^{\circ} 08^{\prime} 01.8^{\prime \prime}$ O.

Gymnotus sylvius [como Gymnotus carapo Linnaeus 1758 em Giamas et al. (2004), —da Silva et al. (2006); Figura 4r]: MZUSP 86935, 1 ex., rio Tietê, área da Mineradora VCN, 23 34'04.5" S e 460 00' 38.4” O; DZSJRP 12822, 1 ex., canal de acesso ao reservatório Jundiaí, Mogi das Cruzes, $23^{\circ} 38^{\prime} 26.3^{\prime \prime} \mathrm{S}$ e $46^{\circ} 08^{\prime} 01.8^{\prime \prime} \mathrm{O}$.

Hisonotus depressicauda [como Hisonotus sp. em da Silva et al. (2006); Figura 4i]: MZUSP 59110, 6 ex., rio Paraitinga, ao lado da avenida

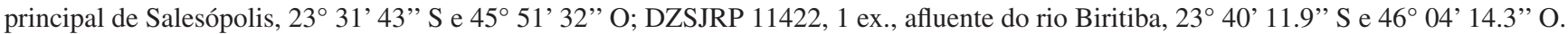

Hollandichthys multifasciatus (Figura 3q): MZUSP 86924, 2 ex., rio Tietê, área da Mineradora VCN, Biritiba Mirim, 23³4'04.5” S e

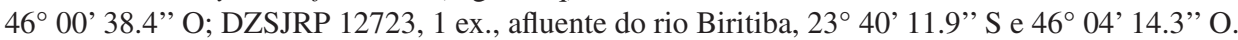

Hoplias intermedius (Figura 3z): MZUSP s/n, 1 ex., reservatório de Ponte Nova, Salesópolis, 23 35' 55.4” S e 45 58’ $02.1^{\prime}$ ” O. 
Ictiofauna do rio Tietê

Hoplias cf. malabaricus (Figura 3aa): MZUSP 26878, 1 ex., lagoa marginal do rio Tietê, Km 16 da estrada Mogi-Salesópolis, Salesópolis,

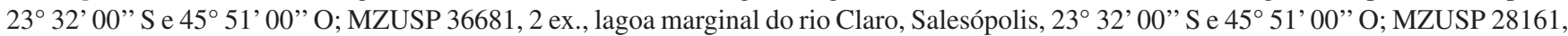

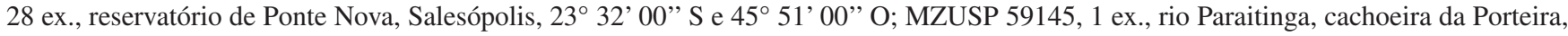
Salesópolis, $23^{\circ} 31^{\prime} 37^{\prime}$ ' S e 45 45' 52'" O.

Hoplosternum cf. littorale (Figura 4e): DZSJRP 12849, 2 ex., reservatório de Ponte Nova, 23 35'06.6" S e 45 58' $21.6^{\circ}$ " O.

Hyphessobrycon cf. anisitsi (Figura 3r): MZUSP 36683, 3 ex., afluente do rio Claro, Salesópolis, 23 32'00" S e 45 51'00" O.

Hyphessobrycon bifasciatus (Figura 3s): MZUSP 102803, 5 ex., rio Tietê, área da Mineradora VCN, Biritiba Mirim, $23^{\circ} 34^{\prime} 05^{\prime}$ 'S e 46 00' 38" O; MZUSP 53667, 1 ex., córrego na estrada para Taiaçupeba, a 2 km do reservatório de Taiaçupeba, Mogi das Cruzes; MZUSP 59129, 1 ex., rio Paraitinga, cachoeira da Porteira, Salesópolis, 23 31' 37' S e 45 45' 52”' O; MZUSP 28155 , 26 ex., reservatório de Ponte Nova, Salesópolis, $23^{\circ} 32^{\prime}$ 00”' S e 45 51'00”' O; DZSJRP 12818, 3 ex., canal de acesso ao reservatório Jundiaí, Mogi das Cruzes, $23^{\circ} 38^{\prime} 26.3^{\prime \prime} \mathrm{S}$ e $46^{\circ} 08^{\prime} 01.8^{\prime \prime} \mathrm{O}$.

Hyphessobrycon duragenys (Figura 3t): nenhum exemplar examinado.

Hyphessobrycon eques (Figura 3u): MZUSP 53668, 5 ex., córrego na estrada para Taiaçupeba, a 2 km do reservatório de Taiaçupeba,

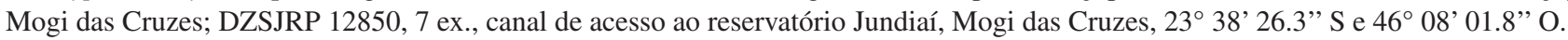

Hyphessobrycon flammeus (Figura 3v): MZUSP 102799, 5 ex., rio Tietê, área da Mineradora VCN, Biritiba Mirim, 23³4’04.5" S e $46^{\circ} 00^{\prime} 38.4$ " O.

Hypostomus ancistroides [como Hypostomus tietensis (Ihering 1905) em Langeani (1989); Figura 4k]: MZUSP 24988,1 ex., estrada SP $88,61 \mathrm{~km}$, Mogi das Cruzes, $23^{\circ} 30^{\prime} 00^{\prime \prime} \mathrm{S}$ e $46^{\circ} 12^{\prime} 00^{\prime \prime} \mathrm{O}$.

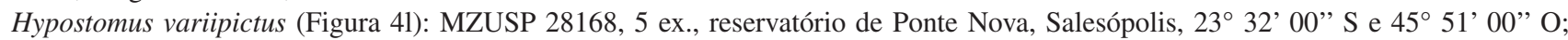
DZSJRP 12830, 1 ex., reservatório de Biritiba, Biriba Mirim, 23 36' 12.2" S e 46 $05^{\prime} 27.0^{\prime \prime} \mathrm{O}$.

Imparfinis piperatus [como Imparfinis sp. em Langeani (1989); Figura 4n): MZUSP 59108, 2 ex., rio Tiête, primeira ponte após a nascente na

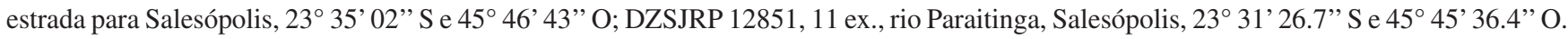

Micropterus salmoides: vários exemplares não preservados do reservatório de Ponte Nova.

Neoplecostomus paranensis [como Neoplecostomus sp. Langeani (1989); Figura 4g]: MZUSP 87141, 6 ex., rio Claro, Poço Verde, Salesópolis; MZUSP 59118, 1 ex., rio Tiête, estrada para Salesópolis, na primeira ponte após a nascente, Salesópolis, 23 35' 02” S e 45 46’ 43" O; DZSJRP 11420, 13 ex., rio Paraitinga, Salesópolis, 2331'26.7’' S e 45 45'36.4”' O.

Oligosarcus paranensis (Figura 3w): MZUSP 87139, 2 ex., rio Claro, Poço Verde, Salesópolis; MZUSP 86928, 2 ex., rio Tietê, área da Mineradora VCN, Biritiba Mirim, 23 34' 04.5' S e 46º0' 38.4” O; MZUSP 25833, 8 ex., rio Paraitinga, a 3 km 3 da estrada

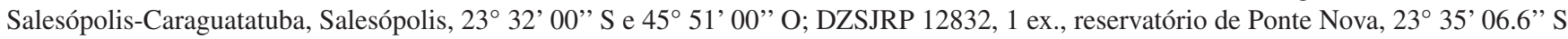
e $45^{\circ} 58^{\prime} 21.6$ " O.

Oreochromis niloticus (Figura 5f): DZSJRP 12837, 2 ex., reservatório Jundiaí, Mogi das Cruzes, 23³7’37.9”' S e 46 12’ 15.6” O; vários exemplares não preservados dos reservatórios de Ponte Nova e Taiçupeba.

Pareiorhina sp. (Figura 4h): MZUSP 74654, 1 ex., ribeirão Venerando, afluente do rio Claro, Estação Biológica da Boracéia, Salesópolis, $23^{\circ} 39^{\prime} 09^{\prime \prime} \mathrm{S}$ e $45^{\circ} 53$ ' 26"' O.

Phalloceros harpagos [como Phalloceros caudimaculatus (Hensel 1868) em Castro \& Arcifa (1987), Langeani (1989), da Silva et al. (2006); Figura 5a]: MZUSP 102802, 4 ex., rio Tietê, área da Mineradora VCN, Biritiba Mirim, 2334'05" S e 46 $00^{\circ} 38^{\prime}$ " O.

Phalloceros reisi [como Phalloceros caudimaculatus em Castro \& Arcifa (1987), Langeani (1989), da Silva et al. (2006); Figura 5bMZUSP 78088, 3 ex., afluente do rio Claro, Estação Biológica de Boracéia, Salesópolis; MZUSP 59113, 5 ex., rio Paraitinga, cachoeira da Porteira, Salesópolis, $23^{\circ} 31^{\prime}$ 37' S e 45 45' 52' O; MZUSP 59134, 4 ex., rio Tiête, primeira ponte após a nascente na estrada para Salesópolis, $23^{\circ} 35^{\prime} 02^{\prime \prime} \mathrm{S}$ e $45^{\circ} 46^{\prime} 43^{\prime \prime} \mathrm{O}$.

Piabina anhembi

Pimelodella meeki (Figura 4o): MZUSP 24823, 12 ex., reservatório de Salesópolis, 45 51'00" O-23 32' 00” S; MZUSP 28165,

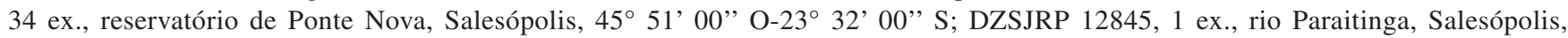
$45^{\circ} 47^{\prime} 18.4$ " O- $23^{\circ} 31^{\prime} 29.8^{\prime \prime} \mathrm{S}$.

Platanichthys platana (Figura 3a): DZSJRP 12718, 10 ex., reservatório Taiaçupeba, Mogi das Cruzes, 2339'08.7" S e 46 10' $12.0^{\circ}$ ” O.

Pseudocorynopoma heterandria (Figura 3k): MZUSP 28156, 91 ex., reservatório de Ponte Nova, Salesópolis, 23 32'00" S e 455 51'00" O; MZUSP 19909, 8 ex., reservatório de Taiaçupeba, Mogi das Cruzes, 2335' 00" S e 46 13' 00" O; DZSJRP 11427, 2 ex., rio Tietê, na ponte Santa Catarina, Biritiba Mirim, 233' 21.6' S e 46 02' 26.8' O; DZSJRP 12809, 1 ex., afluente do rio Biritiba, 23 40' $11.9^{\prime \prime}$ S e 46 04' 14.3" O.

Pseudotocinclus tietensis (Figura 4j): DZSJRP 12811, 2 ex., afluente do rio Biritiba, 2340' 11.9"' S e 46 04' 14.3" O; DZSJRP 12841,

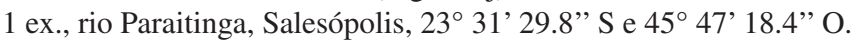

Rhamdia cf. quelen [como Rhamdia hilarii Valenciennes, 1840 em Giamas et al. (2004), como Rhamdia sp. em Langeani (1989); Figura 4p]: MZUSP 36634, 27 ex., fluente do rio Claro, adutora da SABESP, Salesópolis, 23 32' 00" S e 45 51'00' O; MZUSP 28166,

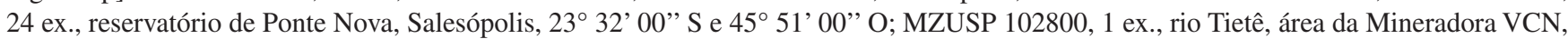
Biritiba Mirim, $23^{\circ} 34^{\prime} 05^{\prime \prime} \mathrm{S}$ e $46^{\circ} 00^{\prime} 38^{\prime \prime} \mathrm{O}$

Salminus hilarii (Figura 3y): MZUSP 86921, 3 ex., rio Tietê, área da Mineradora VCN, Biritiba Mirim, 23³4'04.5” S e 46º 00' $38.4^{\circ}$ ” O. Scleromystax barbatus (Figura 4f): MNRJ 36792, 1 ex. rio Biritiba, 2340'25.8' S e 4604' 53.8”' O.

Serrapinnus notomelas (Figura 3h): MZUSP 53664, 73 ex., córrego na estrada para Taiaçupeba, a 2 km do reservatório de Taiaçupeba, Mogi das Cruzes; MZUSP 86930, 8 ex., rio Tietê, área da Mineradora VCN, Biritiba Mirim, 23 34'04.5" S e 46 00' 38.4" O; DZSJRP 12725, 7 ex., canal de acesso ao reservatório Jundiaí, Mogi das Cruzes, $23^{\circ} 38^{\prime} 26.3^{\prime \prime}$ S e $46^{\circ} 08^{\prime} 01.8^{\prime \prime}$ O.

Spintherobolus papilliferus (Figura 3i): DZSJRP 2244, 1 ex., rio Claro, Estação Biológica de Boracéia, Salesópolis, 23.5 57’ 78” S e $45^{\circ} 74^{\prime \prime} 05^{\prime \prime} \mathrm{O}$. 
Synbranchus cf. marmoratus (Figura 5i): MZUSP 86938, 1 ex., rio Tietê, área da Mineradora VCN, Biritiba Mirim, $23^{\circ} 34^{\prime} 04.5^{\prime \prime} \mathrm{S}$ e $46^{\circ} 00^{\prime} 38.4^{\prime \prime} \mathrm{O}$.

Taunayia bifasciata (Figura 4q): MZUSP 36633, 16 ex., afluente do rio Claro, adutora da SABESP no rio Claro, Salesópolis, $23^{\circ} 32^{\prime} 00^{\prime \prime} \mathrm{S}$ e $45^{\circ} 51^{\prime} 00^{\prime \prime} \mathrm{O}$.

Tilapia rendalli (Figura 5g): DZSJRP 12815, 1 ex., canal de acesso ao reservatório Jundiaí, Mogi das Cruzes, 23³8’26.3” S e 4608'01.8”' O; vários exemplares não preservados dos reservatórios de Ponte Nova e Taiçupeba.

Trichomycterus iheringi [como Trichomycterus sp1 em Langeani (1989); Figura 4a]: MZUSP 26886, 4 ex., rio Tiete, km 18 da estrada Mogi-Salesópolis, Mogi das Cruzes, 23 30' 00"' S e 46 12' 00” O; MZUSP 59120, 1 ex., rio Paraitinga, acima da cidade de Salesópolis, $23^{\circ} 31$ ' 26" S e 45 48' 09' O; MZUSP 87585, 1 ex., rio Claro, ponte da estrada para a sede da Estação Biológica de Boracéia, Salesópolis, $23^{\circ} 38^{\prime} 59^{\prime \prime} \mathrm{S}$ e $45^{\circ} 54^{\prime} 39^{\prime}$ ' O.

Trichomycterus paolence (Figura 4b): MZUSP 87578, 1 ex., rio Guaratuba, afluente do rio Claro, Estação Biológica de Boracéia, Salesópolis, $23^{\circ} 40^{\prime} 03^{\prime \prime} \mathrm{S}$ e $45^{\circ} 53^{\prime} 47^{\prime \prime} \mathrm{O}$. 